\title{
Hartree-Fock Instabilities and Electronic Properties
}

\section{DOMINIQUE DEHARENG, GEORGES DIVE}

Centre d'Ingéniérie des Protéines, Institut de Chimie B6, Sart Tilman, B-4000 Liège 1, Belgium

Received 17 September 1999; accepted 8 December 1999

\begin{abstract}
Hartree-Fock instabilities are investigated for about 80 compounds, from acetylene to mivazerol (27 atoms) and a cluster of 18 water molecules, within a double $\zeta$ basis set. For most conjugated systems, the restricted Hartree-Fock wave function of the singlet fundamental state presents an external or so-called triplet instability. This behavior is studied in relation with the electronic correlation, the vicinity of the triplet and singlet excited states, the electronic delocalization linked with resonance, the nature of eventual heteroatoms, and the size of the systems. The case of antiaromatic systems is different, because they may present a very large internal Hartree-Fock instability. Furthermore, the violation of Hund's rule, observed for these compounds, is put in relation with the fact that the high symmetry structure in its singlet state has no feature of a diradical-like species. It appears that the triplet Hartree-Fock instability is directly related with the spin properties of nonnull orbital angular momentum electronic systems. (c) 2000 John Wiley \& Sons, Inc. J Comput Chem 21: 483-504, 2000
\end{abstract}

Keywords: Hartree-Fock instabilities; resonance; $\pi$-electronic systems; antiaromatic systems; violation of Hund's rule 


\section{Introduction}

H artree-Fock (HF) instabilities have been well known since the sixties. ${ }^{1-22}$ In this introduction, we shall present only a brief summary.

Let us consider even electronic systems, $2 \mathrm{~N}$ being the total number of electrons. The HF framework can be considered at several restraint levels. The most often used one is the restricted HF (RHF) scheme in real coordinate space (RRHF) where the electrons are paired in molecular orbitals (MO); in that case, the HF monodeterminantal wave function (w.f.) is constructed from $N$ real one-electron functions each of which gives rise to two spin orbitals by multiplication by the $\alpha$ or $\beta$ spin function. This type of w.f. is an eigenfunction of the total spin squared operator $S^{2}$ and of the $z$-projection $S_{z}$, i.e.,

$$
S^{2} \psi=s(s+1) \hbar^{2} \psi, \quad S_{z} \psi=m_{s} \hbar \psi,
$$

with $s=m_{s}=0, \hbar=h /(2 \pi), h$ being the Planck constant.

The variation calculus ${ }^{23}$ leads to a RRHF wave function that is a stationary solution of the Schrödinger equation within the constrained framework adopted.

Some of the restrictions of this RRHF scheme can be lifted. One can use a distinct spatial function for each $\alpha$ and $\beta$ spin orbital (s.o.), thus working at the unrestricted HF (UHF) level, ${ }^{24}$ one can consider complex functions instead of real ones (CRHF or CUHF levels) and, at last, one can choose monoelectronic functions that are no longer pure $\alpha$ or $\beta$ s.o. but are a mixture of both; this latter framework is called the generalized HF level (RGHF or CGHF). Except in CRHF, the w.f. obtained in these frameworks is no longer an eigenfunction of $S^{2}$, but the UHF w.f. is still an eigenfunction of $S_{z}$.

The general strategy is to find a stationary solution within a chosen HF level, to ascertain that it is a minimum, then to pass to a less restricted level, to check for stability of the wave function within this new framework, and to reoptimize it if it presents an instability.

As pointed out by several authors (for instance refs. 1, 12, 18, and 25), the instability matrices are directly related with those obtained in the random phase approximation (RPA) or the time-dependent HF (TDHF) frameworks. ${ }^{1,25}$

The HF instabilities were classified by Fukutome, ${ }^{11}$ according to the (spin rotation $\otimes$ time reversal) subgroups, into eight classes in direct connection with those cited above, R(C)RHF, R(C)UHF, and so on.
Some of these instabilities are recognized as trivial ones. The first type are those related with the fact that the HF w.f. obtained corresponds to an excited state. These are denoted as "filling up" instabilities by Chambaud et al. ${ }^{15}$ and correspond to internal ones, because the chosen HF framework, be it RHF or UHF, does not change. Other trivial instabilities are those found for nonsinglet states when passing from the restricted open shell (ROHF) ${ }^{26}$ to the UHF framework, as emphasized by Paldus and Cizek ${ }^{8}$ and by Hilbert and Coulson, ${ }^{17}$ because UHF always produces lower energies than ROHF; these instabilities are external ones, because the framework has been changed (ROHF $\rightarrow$ UHF). In this framework, the case of the allyl radical has been a matter of discussion. ${ }^{27}$

For closed-shell systems, external (RHF $\rightarrow$ UHF) instabilities were called triplet instabilities for the first time by Cizek and Paldus, ${ }^{5}$ and this nomenclature still remains.

For particular singlet entities named 1,3-dipoles, it is also well known that a UHF solution provides a lower energy than the RHF one, ${ }^{19-22}$ due to the diradicalar character of the singlet fundamental state. As a reminder, 1,3-dipoles are generally represented as resonant structures between zwitterions and singlet diradicals as in the following example:

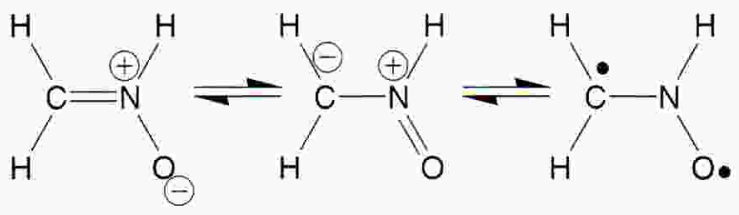

The HF instabilities are also related to the symmetry dilemma as emphasized by Löwdin ${ }^{3,7}$ stating that a w.f. with MOs belonging to a lower symmetry point group than that related with the geometry could lead to a lower energy. This symmetry breaking dilemma is also encountere ${ }^{28}$ in the framework of the density functional theory (DFT). ${ }^{29}$

The aim of this work is to search for some relationships between the nature of the molecular systems and the existence or absence of HF instabilities. Such links cannot be found by considering only a few molecules. Thus, a large number of systems has to be investigated. The investigated species are all even electronic molecules or ions and most of our work deals with the so-called triplet, or external, instabilities. Moreover, RHF internal instabilities were also investigated for the high-symmetry annulenes, i.e., cyclic polyenes, because it was predicted, on a semiempirical basis, , ,16 that this type of instability should appear for large systems. Also, UHF internal instabilities were in- 


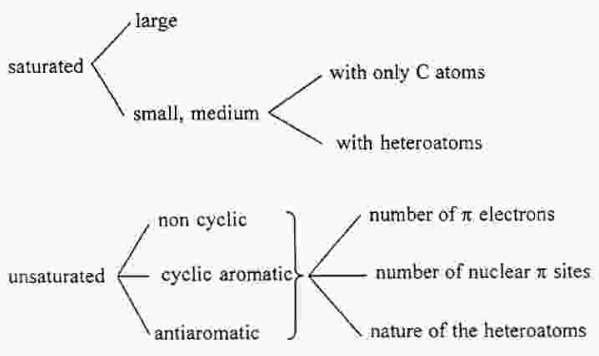

CHART 1.

vestigated for some systems called antiaromatics according to the Hückel classification, ${ }^{30}$ i.e., annulenes with $4 n \pi$ electrons. Thus, the HF instabilities were investigated for some saturated compounds and for unsaturated ones. In this latter series, the compounds were considered within very distinct classes, noncyclic compounds, aromatic, and antiaromatic entities. The HF instability was studied as a function of the number of $\pi$ electrons, the number of heavy nuclei underlying the $\pi$ delocalization, the nature of the heteroatoms involved, as summarized in Chart 1.

The second and third sections of this work present a brief theoretical background, the details of which can be found in refs. $1-15$, and the computational tools used. The fourth section deals with some peculiar points of the optimized geometries. Finally, the fifth section is split into subsections presenting the results and their discussion, firstly as general comments, secondly as a function of the nature of the systems investigated.

\section{Theoretical Background}

Let $\Psi_{0}$ be the self-consistent HF monodeterminantal wave function and $\Psi$ the general multideterminantal wave function for which $\Psi_{0}$ is expected to be a good approximation. $\Psi$ can be expanded in terms of all the determinants constructed with the occupied and virtual molecular spin orbitals (m.s.o.) derived from the self-consistent field (SCF) scheme in the $\mathrm{LCAO}-\mathrm{MO}$ framework:

$$
\begin{aligned}
\Psi=\Psi_{0} & +\sum_{i}^{\text {occ }} \sum_{a}^{\text {virt }} D_{i \rightarrow a} \Psi_{i \rightarrow a} \\
& +\sum_{i}^{\text {occ }} \sum_{j}^{\text {occ virt virt }} \sum_{a} \sum_{b} D_{i \rightarrow a, j \rightarrow b} \Psi_{i \rightarrow a, j \rightarrow b}+\cdots
\end{aligned}
$$

$\Psi_{i \rightarrow n}$ is the wave function, the determinant of which contains the virtual s.o. $\chi_{a}$ instead of the occupied one $\chi_{i}$, corresponding to a monoexcitation of the reference state $\Psi_{0}, \Psi_{i \rightarrow a, j \rightarrow b}$ corresponds to a diexcitation $\chi_{i} \rightarrow \chi_{a}$ and $\chi_{j} \rightarrow \chi_{b}$, and so on, the $D_{i \rightarrow a}$ represent the expansion coefficients describing single excitations from the occupied MO $i$ to the virtual MO $a$, the $D_{i \rightarrow a, j \rightarrow b}$ represent the expansion coefficients describing double excitations from the occupied MOs $i, j$ to the virtual ones $a, b$.

In the framework of the single particle propagator used in the RPA, ${ }^{1,25}$ the coefficients $D_{i \rightarrow a, j \rightarrow b}$ factorizes into the product $D_{i \rightarrow a} D_{j \rightarrow b}$.

The sign of the second-order energy term $E_{2}$ obtained for $\Psi$ must be positive as a necessary condition for stability. ${ }^{1-15}$ In the RPA framework, one obtains:

$$
\begin{aligned}
E_{2} & =\frac{1}{2}\left(D, D^{*}\right)\left(\begin{array}{cc}
A & B \\
B^{*} & A^{*}
\end{array}\right)\left(\begin{array}{c}
D \\
D^{*}
\end{array}\right) \\
& =\frac{1}{2}\left(D, D^{*}\right) \mathcal{H}\left(\begin{array}{c}
D \\
D^{*}
\end{array}\right)
\end{aligned}
$$

$$
\begin{array}{ll}
\mathbf{D}=\left\{D_{s}\right\} & \\
\mathbf{A}=\left\{A_{\mathrm{st}}\right\}, & A_{\mathrm{st}}=\langle s|V| t\rangle=\left(\varepsilon_{a}-\varepsilon_{i}\right) \delta_{\mathrm{st}}+(a j|| i b) \\
\mathbf{B}=\left\{B_{\mathrm{st}}\right\}, & B_{\mathrm{st}}=\langle\mathrm{st}|V| 0\rangle=(a b|| i j),
\end{array}
$$

the * superscript referring to the complex conjugate matrix,

$$
\begin{aligned}
s & \equiv i \rightarrow a, \quad t \equiv j \rightarrow b \\
V & =H-\langle 0|H| 0\rangle,
\end{aligned}
$$

$H$ being the electronic hamiltonian, and $|0\rangle$ the representation of $\Psi_{0}, \varepsilon_{i}$ are the eigenvalues of the one-electron Fock operator and $(a j \| i b)$ are the usual bielectronic integrals

$$
\iint \chi_{a}(1) \chi_{b}(2)\left(1 / r_{12}\right)\left[\chi_{i}(1) \chi_{j}(2)-\chi_{j}(1) \chi_{i}(2)\right] d \tau_{1} d \tau_{2} \text {. }
$$

Thus, the stability of the HF w.f. is defined according to the inertia of the $\mathcal{H}$ matrix, i.e., to the number of its negative eigenvalues: no negative eigenvalue of the $\mathcal{H}$ matrix means that the investigated system has a stable HF w.f. The A matrix elements involve monoexcited states couplings, while the $\mathbf{B}$ matrix elements couple diexcited states with the fundamental one.

The eigenvector(s) corresponding to the negative eigenvalue(s) of $\mathcal{H}$ are used to construct a generalized Fock matrix the diagonal elements of which are molecular orbital energy differences, and the off diagonal elements are functions of the instability eigenvector. By diagonalizing this new Fock matrix, a set of trial s.o. is obtained in the new framework. ${ }^{10}$

It can be shown ${ }^{8-10}$ that the $\mathbf{A}$ and $\mathbf{B}$ matrices factorize into spin conserved $\left(\mathbf{A}^{\prime}, \mathbf{B}^{\prime} \rightarrow \mathcal{H}^{\prime}\right)$ and spinunconserved $\left(\mathbf{A}^{\prime \prime}, \mathbf{B}^{\prime \prime} \rightarrow \mathcal{H}^{\prime \prime}\right)$ parts. The internal HF instabilities result from the appearance of negative 
eigenvalues for $\mathcal{H}^{\prime}$ and external ones from the occurrence of negative eigenvalues for $\mathcal{H}^{\prime \prime}$. For even electronic systems, the internal instabilities are often called singlet instabilities, while external ones are referred to as triplet instabilities. Singlet instabilities appear when, remaining in the RHF framework, one can find a lower energy RHF w.f. than that initially obtained in a self-consistent way. Triplet instabilities appear when one can find a lower energy UHF w.f. than that initially obtained in a RHF self-consistent way.

\section{Computational Tools}

All the calculations were performed with the Unix version of GAUSSIAN94 $4^{31}$ on three computers, Dec- $\alpha$ servers 4 and 8 processors, 4100 and 8400 , and a R4400 SGI. The excited states were determined either at the HF level, or at the singly excited configuration level (CIS), ${ }^{32}$ or even at a multiconfigurational SCF level labeled CASSCF (complete active space SCF). ${ }^{33} \mathrm{~A}$ few calculations were performed at the post Hartree-Fock perturbational Møller-Plesset ${ }^{34}$ level, either at the second order (MP2) or the fourth order (MP4).

\section{Optimized Geometries: Energetical and Geometrical Considerations}

The stability of the RHF-self-consistent (SCF) wave function was investigated in the UHF framework for seven fully saturated compounds as well as for seventy nine unsaturated ones (see Appendix). The geometry of these molecules or ions, in their lowest singlet state, was optimized, at the RHF-SCF level, within a chosen symmetry point group (SG), but the nuclear arrangement obtained at convergence was not necessarily a zero-order (minimum) or even a higher order critical point (see the following). The $\mathrm{C}_{2 \mathrm{v}}$-planar cis-butadiene// (RHF, $6-31 \mathrm{G}^{* *}$ ) singlet structure is a transition state (TS) for which the imaginary frequency is equal to $162.61 \mathrm{~cm}^{-1}$. The singlet state structures of the high symmetry $\left(\mathrm{D}_{x \mathrm{~h}}\right) x$-annulenes $(x=10,14,18)$ are not minima, but are higher order critical points, i.e., are characterized by a null gradient and a hessian with one or several negative eigenvalue(s). Finally, the antiaromatic systems RHF singlet state geometries optimized within the high SG restraints are not critical points: it is not possible to obtain a null gradient with these geometrical constraints.
The $x$-annulenes $(x>6)$ in their highest planar $\mathrm{SG}$, corresponding to identical $\mathrm{C}-\mathrm{C}$ bond lengths, are considerably much higher in energy than any local minimum. For instance, for the optimized geometries obtained at the RHF/6-31G level, An10 $\left(D_{10 h}\right)$ is $125.386 \mathrm{~kJ} / \mathrm{mol}$ higher than $\operatorname{An} 10\left(C_{2}\right)$, An14 $\left(D_{14 h}\right)$ is $919.488 \mathrm{~kJ} / \mathrm{mol}$ higher than An14 $\left(C_{1}\right)$, An18 $\left(D_{1.8 h}\right)$ is $1814.094 \mathrm{~kJ} / \mathrm{mol}$ higher than An18 $\left(C_{1}\right)$. This is to be put in relation with the distortive property of the $\pi$ electrons that counterbalance the symmetrizing trend of the $\sigma$ ones. Indeed, it has been shown by several authors ${ }^{35}$ that the $\sigma$ electrons bring a nuclear system to a symmetrical structure with all the $\mathrm{C}-\mathrm{C}$ bonds equal, while the $\pi$ electrons show a distortive behavior leading to a single/double bond alternance. The equilibrium geometry results from the equilibration of the two opposite trends. Thus, if benzene equilibrium structure has a $\mathrm{D}_{6 \mathrm{~h}} \mathrm{SG}$, it is due to the stronger influence of the $\sigma$ electronic frame, and the $\pi$ electronic delocalization responsible for the resonance stabilizing energy is actually a byproduct of the symmetric structure.

At the RHF/6-31G level, An10 ( $\left.\mathrm{D}_{10 \mathrm{~h}}\right)$ and An14 $\left(D_{14 h}\right)$ are critical points of order 3 and 5 , respectively. Among all the imaginary frequencies, the unique non degenerate one is the highest in absolute value. So, for An10 $\left(\mathrm{D}_{10 \mathrm{~h}}\right)\left(\mathrm{An} 14\left(\mathrm{D}_{14 \mathrm{~h}}\right)\right)$, the imaginary frequency equal to $i 294.0 \mathrm{~cm}^{-1}\left(\mathrm{i} 2863.8 \mathrm{~cm}^{-1}\right)$ corresponds to the nondegenerate normal mode related with the formation of alternant single and double bonds. The An18 ( $\left.\mathrm{D}_{18 \mathrm{~h}}\right)$ critical point of order 8 has only degenerate imaginary frequencies related to out-of-plane deformations, and the normal mode describing the single-double bonds alternation is a degenerate mode at the real frequency of $1692.7 \mathrm{~cm}^{-1}$. From these energetical considerations, the first step in the distortion of $\operatorname{An10}\left(\mathrm{D}_{10 \mathrm{~h}}\right)$ and $\mathrm{An} 14\left(\mathrm{D}_{14 \mathrm{~h}}\right)$ is the appearance of single/double bond alternance, while for An18 $\left(D_{18 \mathrm{~h}}\right)$, it is out-ofplane folding.

For several systems, the CASSCF level was also used for the geometry optimization as well as for the determination of singlet and/or triplet excited states. Except in one case (the cyclopentadienyl anion Cpdm1), all the active molecular orbitals (MOs) were chosen to be $\pi$ and $\pi^{*}$ ones. In the case of unsaturated compounds, the lowest transitions are most often of the type $\pi \rightarrow \pi^{*}$ and the choice of such an active space seems to be adequate. Nevertheless, for some exceptions like Cpdm1, there are a lot of $\pi \rightarrow \sigma^{*}$ transitions before or in between the $\pi \rightarrow \pi^{*}$ ones. Thus, several choices of active MO were done with, at least the one containing $\sigma \mathrm{MOs}^{36}$ 
It remains true that the choice of a reliable active space is a serious problem because the CASSCF convergence is very dependent on it.

\section{Results and Discussion}

The investigated systems are not all planar, and the MOs cannot be systematically designated as $\sigma$ or $\pi$ by reference to their symmetry according to an eventual symmetry plane, as usual in organic chemistry. For instance, in the case of twisted-butadiene $\left(C_{2}\right), \operatorname{An} 10\left(C_{2}\right), \operatorname{An} 14\left(C_{1}\right), \operatorname{An} 18\left(C_{1}\right)$, or mivazerol, it is no longer sensible to speak of $\pi$ MOs but only of MOs related with the unsaturated bonds because no symmetry plane exists. However, for the sake of conciseness, they will also be refered to as $\pi$ MOs hereafter.

Before considering detailed observations as a function of the size and the nature of the systems, some general comments are presented in the following subsection.

\section{GENERAL COMMENTS}

Among all the investigated compounds (see Appendix), only those presenting an external (RHF $\rightarrow$ UHF) instability are listed in Table I.

The last ones are the mivazerol (27 atoms), and one of its protonated structure; they are benzylimidazoles with an $\alpha 2$ agonist profile. ${ }^{37}$ The basis sets used differ by the presence or the absence of polarization and/or diffuse functions and have in common the 6-31G kernel. An exception is made for the 10-annulene in its global minimum geometry of symmetry $C_{2}$ (ref. 38 ), An10 $\left(C_{2}\right)$, for which a calculation was also done within the double $\zeta$ Dunning D95 basis set. ${ }^{39}$ Table I provides the energy gain $\Delta E$ (reop) obtained after the optimization of the RHF w.f. in the UHF framework. Because that newly reoptimized UHF(reop) wave function is no longer an eigenfunction of the total spin squarred operator $S^{2}$, the mean value $\left\langle S^{2}\right\rangle$ (reop) of that operator for the UHF(reop) wave function is given. Moreover, the CIS triplet excitation energies are shown, as well as the energy difference $\Delta E(\mathrm{~L}-\mathrm{H})$ between the lowest virtual MO (LUMO) and the highest occupied one (HOMO), obtained at the RHF level. The negative eigenvalues $\lambda^{0}(\operatorname{tr})$ of the stability matrix was determined for some compounds. Obviously, the larger the $\lambda^{0}(\operatorname{tr})$ absolute value, the larger $\Delta E$ (reop).

\section{Orders of Magnitude}

The results of Table I clearly show that, for many $\pi$ electron systems, the RHF w.f. is not stable in the UHF framework. The energy gain $\Delta E$ (reop) is of the order of 3-15 kJ/mol for most of the four or six $\pi$ electron compounds. This quantity becomes somewhat higher for the $\mathrm{N}_{6} \mathrm{H}_{x}^{x+}$ cations, the cyclooctatetraene dication Cotp2 $\left(\mathrm{D}_{8 \mathrm{~h}}\right)$, and the fiveand seven-membered rings containing boron. For species with a larger number of $\pi$ electrons, the energy gain can be much higher.

In the case of the annulenes in their highest SG, finding an $\mathrm{HF}$ instability, either external (triplet) or internal (singlet one in this work), becomes more and more obvious as the cycle size grows up because the system is then very high in energy, and is characterized as a critical point of increasing order. Nevertheless, if one compares these systems relaxed down to a local minimum $\left[\operatorname{An} 10\left(C_{2}\right), \operatorname{An} 14\left(C_{1}\right)\right.$, An18 $\left.\left(C_{1}\right)\right]$, the external HF instability remains large (Table I), and increases with the number of unsaturated bonds.

\section{Relation with the LUMO-HOMO Gap}

Fukutome ${ }^{11}$ argued that an HF instability should occur when the energy difference $\Delta E(\mathrm{~L}-\mathrm{H})$ between the HOMO and the LUMO becomes small, thus enabling easy electronic transitions, usually $\pi \rightarrow \pi^{*}$ ones. As seen from Table I, the LUMO-HOMO gap ranges in the order of $600-1300 \mathrm{~kJ} / \mathrm{mol}$ when an HF instability occurs. Such large numbers are of the order of magnitude of the $\mathbf{A}$ and $\mathbf{B}$ matrix elements [eq. (2)]. Thus, it remains that the relation between the LUMO-HOMO gap and the occurrence of an HF instability is qualitative, or semiquantitative when taking the elements of $\mathbf{A}$ or $\mathbf{B}$ as references.

\section{Appearance of Atomic Spin Density (ASD)}

The reoptimized UHF w.f. presents, in nearly all cases, alternant spin densities on the atomic framework involved in the $\pi$ delocalization. This corresponds to the magnetically fully ordered lowest state, as emphasized by Yamaguchi: ${ }^{40}$ spins up and spins down are regularly alternating. Large atomic spin densities (ASDs) of the UHF reoptimized w.f. means a significant electronic localization around the nuclear site. Schütt and Böhm ${ }^{35 c}$ showed that the localization of the $\pi$ electrons around each nucleus was linked to the electronic correlation: the larger the correlation, the stronger the localization, and thus, the larger the ASDs. 
TABLE I.

Systems, among Those Listed in Appendix, Presenting a RHF $\rightarrow$ UHF External Instability.

\begin{tabular}{|c|c|c|c|c|c|}
\hline Molecular System (SG) & $\lambda^{0}(\mathrm{tr})$ & $\Delta E$ (reop) & $\left\langle S^{2}\right\rangle$ (reop) & $\Delta E(\operatorname{tr}, \mathrm{ClS})$ & $\Delta E(\mathrm{~L}-\mathrm{H})$ \\
\hline Ethylene $\left(D_{2 h}\right)(a)$ & -11.55 & -0.10 & 0.03 & 349.4 & 1449.0 \\
\hline trans-Butadiene $\left(\mathrm{C}_{2 h}\right)$ & -70.82 & -6.51 & 0.34 & 274.4 & 1192.9 \\
\hline Twisted butadiene $\left(\mathrm{C}_{2}\right)$ & -45.04 & -2.83 & 0.24 & 295.8 & 1230.9 \\
\hline cis-Butadiene $\left(\mathrm{C}_{2 \mathrm{v}}\right)(\mathrm{TS})$ & -81.21 & -8.70 & 0.40 & 252.3 & 1166.5 \\
\hline Butadiyne & -21.85 & -1.05 & 0.19 & & 1327.9 \\
\hline Truncated cephalosporine (a) & -3.94 & -0.01 & 0.014 & 329.4 & 1168.2 \\
\hline Cyclopropene (a) & -17.69 & -0.24 & 0.05 & 338.5 & 1395.5 \\
\hline $\mathrm{BC}_{4} \mathrm{H}_{5}\left(\mathrm{C}_{2 \mathrm{v}}\right)$ & & -23.45 & 0.64 & 130.0 & 953.8 \\
\hline trans-E, $\mathrm{E}$ hexatriene $\left(\mathrm{C}_{2 h}\right)$ & -109.16 & -20.38 & 0.67 & 228.8 & 1045.7 \\
\hline cis- $\mathrm{E}, \mathrm{E}$ hexatriene $\left(\mathrm{C}_{2 \mathrm{v}}\right)$ & & -19.95 & 0.67 & 230.8 & 1055.9 \\
\hline cis- $E, Z$ hexatriene & -81.14 & -11.41 & 0.53 & 257.2 & 1108.6 \\
\hline Fulvene $\left(\mathrm{C}_{2 \mathrm{v}}\right)$ & -68.50 & -7.42 & 0.42 & 221.9 & 1031.0 \\
\hline Furane $\left(\mathrm{C}_{2 v}\right)(\mathrm{a})$ & -16.92 & -0.38 & 0.09 & 340.6 & 1289.3 \\
\hline Protonated furane $\left(\mathrm{C}_{2 \mathrm{v}}\right)$ & & -2.40 & 0.21 & 319.3 & 1287.6 \\
\hline Thiophene $\left(\mathrm{C}_{2 v}\right)$ & -15.59 & -0.35 & 0.09 & 325.5 & 1222.8 \\
\hline Protonated thiophene $\left(\mathrm{C}_{2 \mathrm{v}}\right)$ & & -2.05 & 0.20 & 319.7 & 1247.3 \\
\hline Thiazole $\left(\mathrm{C}_{\mathrm{s}}\right)$ & -3.77 & -0.02 & 0.02 & 344.5 & 1236.3 \\
\hline Benzene $\left(D_{6 h}\right)(a)$ & -74.39 & -9.12 & 0.47 & 332.3 & 1265.7 \\
\hline (b) & -65.47 & -7.16 & 0.42 & 334.6 & 1259.8 \\
\hline (c) & & -5.02 & 0.36 & 336.0 & 998.4 \\
\hline Pyrimidine $\left(\mathrm{C}_{\mathrm{s}}\right)$ & & -2.78 & 0.29 & 383.7 & 1281.0 \\
\hline Pyridine $\left(\mathrm{C}_{\mathrm{s}}\right)$ & & -6.34 & 0.40 & 351.6 & 1235.8 \\
\hline Pyridazine $\left(\mathrm{C}_{2 \mathrm{v}}\right)$ & & -11.22 & 0.50 & 349.6 & 1273.1 \\
\hline $1,2,3$ Triazine $\left(C_{2 v}\right)$ & & -14.15 & 0.55 & 322.3 & 1324.0 \\
\hline Hexazine $N_{6}\left(D_{6 h}, T S\right)$ & & -66.70 & 1.04 & 161.6 & 1195.0 \\
\hline $\mathrm{N}_{6} \mathrm{H}_{2}^{2+}\left(\mathrm{C}_{\mathrm{s}}\right)$ & & -51.84 & 0.97 & 328.4 & 1161.7 \\
\hline $\mathrm{N}_{6} \mathrm{H}_{4}^{4+}\left(\mathrm{C}_{\mathrm{S}}\right)$ & & -74.96 & 1.22 & 313.8 & 1365.5 \\
\hline $\mathrm{C}_{7} \mathrm{H}_{7}^{+}\left(\mathrm{D}_{7 \mathrm{~h}}\right)(\mathrm{a})$ & -7.03 & -0.10 & 0.06 & 326.4 & 1113.9 \\
\hline (b) & -20.56 & -0.84 & 0.16 & 315.2 & 1106.9 \\
\hline $\mathrm{C}_{6} \mathrm{H}_{6} \mathrm{~N}^{+}\left(\mathrm{C}_{2 \mathrm{v}}\right)$ & -15.61 & -0.69 & 0.17 & 331.1 & 1089.9 \\
\hline $\mathrm{C}_{5} \mathrm{H}_{6} \mathrm{NB}\left(\mathrm{t} 1, \mathrm{C}_{\mathrm{s}}\right)(\mathrm{a})$ & & -23.17 & 0.74 & 246.5 & 1064.2 \\
\hline (b) & & -15.99 & 0.64 & 261.0 & 1075.6 \\
\hline $\mathrm{C}_{5} \mathrm{H}_{6} \mathrm{NB}\left(\mathrm{t} 2, \mathrm{C}_{\mathrm{s}}\right)(\mathrm{TS})$ & & -18.17 & 0.65 & 238.4 & 1057.5 \\
\hline $\mathrm{C}_{5} \mathrm{H}_{6} \mathrm{NB}\left(\mathrm{t} 2, \mathrm{C}_{1}\right)$ & & -19.07 & 0.69 & 237.5 & 1064.2 \\
\hline $\mathrm{BC}_{6} \mathrm{H}_{7}\left(\mathrm{C}_{2 v}\right)$ & & -19.53 & 0.69 & 233.8 & 1036.6 \\
\hline Cotp2 $\left(\mathrm{D}_{8 \mathrm{~h}}\right)$ & & -28.22 & 0.87 & 212.4 & 958.5 \\
\hline Naphtalene $\left(D_{2 h}\right)$ & -110.91 & -30.52 & 1.01 & 267.1 & 1023.8 \\
\hline Indole $\left(\mathrm{C}_{\mathrm{S}}\right)$ & & -9.06 & 0.53 & 311.2 & 1094.0 \\
\hline An10 $\left(D_{10 h}\right)$ & & -111.33 & 1.63 & 173.8 & 897.6 \\
\hline An10 $\left(C_{2}\right)(a)$ & & -29.95 & 1.14 & 242.0 & 1059.5 \\
\hline (d) & & -30.52 & 1.16 & & 1034.1 \\
\hline An11p1 $\left(C_{1}\right)$ & & -33.76 & 1.24 & 141.9 & 793.5 \\
\hline An12p2 $\left(C_{1}\right)$ & & -53.32 & 1.44 & 162.9 & 798.8 \\
\hline Anthracene $\left(D_{2 h}\right)$ & & -84.02 & 1.76 & 189.2 & 850.8 \\
\hline Phenanthrene $\left(\mathrm{C}_{2 v}\right)$ & & -57.06 & 1.58 & 259.2 & 998.9 \\
\hline An14 $\left(D_{14 h}\right)$ & & -247.74 & 2.54 & 84.9 & 690.2 \\
\hline An14 $\left(D_{7 h}\right)$ & & -160.53 & 2.36 & 138.8 & 829.2 \\
\hline An14 $\left(C_{1}\right)$ & & -54.50 & 1.68 & 217.7 & 985.5 \\
\hline Naphtacene $\left(D_{2 h}\right)$ & & -141.56 & 2.41 & 134.0 & 736.9 \\
\hline An18 $\left(D_{18 h}\right)$ & -359.30 & -390.77 & 3.42 & 32.6 & 573.9 \\
\hline An18 $\left(D_{9 h}\right)$ & & -211.22 & 3.12 & 129.2 & 789.8 \\
\hline An18 $\left(C_{1}\right)$ & & -105.74 & 2.53 & 190.6 & 905.1 \\
\hline Pentacene $\left(D_{2 h}\right)$ & & -205.76 & 3.05 & 92.2 & 655.1 \\
\hline
\end{tabular}


TABLE I.

\begin{tabular}{|c|c|c|c|c|c|}
\hline Molecular System (SG) & $\lambda^{0}(\mathrm{tr})$ & $\Delta E($ reop) & $\left\langle S^{2}\right\rangle$ (reop) & $\Delta E(\mathrm{tr}, \mathrm{ClS})$ & $\Delta E(L-H)$ \\
\hline Hexacene $\left(D_{2 h}\right)$ & & -274.03 & 3.69 & 60.1 & 594.3 \\
\hline Hexaphene $\left(\mathrm{C}_{\mathrm{S}}\right)$ & & -184.59 & 3.44 & 160.5 & 769.5 \\
\hline Toluene & & -9.13 & 0.47 & 330.4 & 1233.8 \\
\hline Aniline & & -5.30 & 0.38 & 338.1 & 1138.5 \\
\hline Phenol $\left(\mathrm{C}_{\mathrm{s}}\right)(\mathrm{a})$ & & -7.55 & 0.43 & 336.9 & 1200.2 \\
\hline (b) & & -4.88 & 0.36 & 341.8 & 1188.1 \\
\hline Phenolium $\left(\mathrm{C}_{\mathrm{S}}\right)$ & & -7.00 & 0.41 & 343.0 & 1223.9 \\
\hline Phenone & & -10.84 & 0.56 & 295.2 & 1188.6 \\
\hline Salicylamide & & -2.40 & 0.27 & 341.0 & 1085.8 \\
\hline 3-Methyl-indole & & -8.95 & 0.53 & 310.7 & 1083.6 \\
\hline 2-Methyl-indole & & -8.25 & 0.51 & 314.2 & 1085.4 \\
\hline Mivazerol & & -6.36 & 0.42 & 328.4 & 1005.4 \\
\hline Protonated mivazerol & -63.96 & -7.70 & 0.45 & 326.7 & 1102.7 \\
\hline
\end{tabular}

When no symmetry point group (SG) is indicated, $S G$ is $C_{1}$. The first eigenvalue $\lambda^{0}(\operatorname{tr})$ of the spin-unconstrained instability matrix $\mathcal{H}^{\prime \prime}$ is given, in $\mathrm{kJ} / \mathrm{mol}$, for few systems. $\Delta E($ reop) is the energy lowering, in $\mathrm{kJ} / \mathrm{mol}$, from the reoptimization of the RHF wave function within the UHF framework. $\Delta E(\mathrm{tr}, \mathrm{CIS})$ is the energy difference, in $\mathrm{kJ} / \mathrm{mol}$, between the lowest singlet state and the triplet one related with the RHF $\rightarrow$ UHF instability, at the CIS level. $\left\langle S^{2}\right\rangle($ reop) is the average value of the squarred total spin operator obtained for the UHF reoptimized wave function. Except for few cases (ethylene, truncated cephalosporine, cyclopropene, furane, benzene, $\mathrm{C}_{7} \mathrm{H}_{7}^{+}$, $\mathrm{C}_{5} \mathrm{H}_{6} \mathrm{NB}\left(\mathrm{t} 1, \mathrm{C}_{\mathrm{s}}\right)$, An10 $\left(\mathrm{C}_{2}\right)$, phenol), only the results obtained with the largest basis set are presented (see Appendix). Otherwise, see notes. $\triangle E(\mathrm{~L}-\mathrm{H})$ is the LUMO-HOMO energy difference, in $\mathrm{kJ} / \mathrm{mol}$. For the abbreviations, see Appendix.

(a) 6-31G; (b) 6-31G*; (c) 6-31++G**; (d) D95.

\section{Possible Relation with Excited States}

It was found previously, in the case of mivazerol, ${ }^{37}$ that the eigenvector of the $\mathcal{H}$ matrix related with the instability was very similar to the monoexcitation $\mathrm{CI}$ expansion (CIS) vector of the lowest triplet state, expressed in the basis of RHF-MO determinants. Thus, the energy of the triplet state, whose CIS expansion vector is the same as the instability eigenvector, is calculated relative to the fundamental singlet state, at the CIS level $[\Delta E(\operatorname{tr}, \mathrm{CIS})]$. The instability seems to arise when the triplet state, obtained at the CIS level, lies under $350 \mathrm{~kJ} / \mathrm{mol}$ [see $\Delta E(\operatorname{tr}, \mathrm{CIS})$ in Table I]. However, the CIS level is known to provide very approximative excitation energies, and the question remains of the existence of a quantitative relationship between the occurence of an instability and the value of $\Delta E$ (triplet-singlet) evaluated at a higher degree of accuracy than CIS. The triplet energies, relative to the fundamental singlet state, are presented in Table II.

Moreover, the excitation energy of the first excited singlet state was also determined for some molecules. The results are presented in Table III.

Apart from the antiaromatic systems that will be discussed later, and except for Cpdm1, the triplet excited states are significantly lower than the singlet ones. For annulenes with a large number of $\pi$ electrons, like An18, the first excited singlet state, becomes sufficiently near the fundamental one to perturb it and induce an internal RHF instability. It is the only singlet instability found for the investigated systems. The $\mathcal{H}^{\prime}$ negative eigenvalue $\lambda^{0}(\mathrm{sg})$ is equal to $-11.77 \mathrm{~kJ} / \mathrm{mol}$, and one obtains a $\Delta E$ (reop) of $-0.467 \mathrm{~kJ} / \mathrm{mol}$ at the $\mathrm{D}_{18 \mathrm{~h}} \mathrm{RHF}(6-31 \mathrm{G})$ optimized geometry. This was already found at the semiempirical level, within the $\pi$-electron model, by Cisek and Paldus, ${ }^{5}$ who predicted the appearance of a RHF instability for annulenes $\mathrm{C}_{n} \mathrm{H}_{n}$ with $n$ greater than 10 . However, as emphasized by several authors, ${ }^{4,5,8}$ the appearance of the instability depends on the parametrization of the semiempirical framework. At the ab initio level, with a double $\zeta$ basis set like 6-31G, it only occurs when $n \geq 18$, at least for the highly symmetrical planar structures. Let us also point out that, at the $a b$ initio level also, the appearance of the HF instability depends on the quality of the calculation, i.e., on the basis set expansion. For instance, ethylene, furane, or the truncated cephalosporine RHF w.f.s are found unstable within the 6-31G basis set but stable within the $6-31 \mathrm{G}^{* *}$ or $6-31+\mathrm{G}^{*}$ ones.

From Tables II-III, one can observe that the excited singlet state obtained from the same $\pi \rightarrow \pi^{*}$ transitions than the triplet associated with the instability is much higher in energy than the triplet, and even can be only the second or third excited singlet state. Let us consider, for instance, trans-butadiene 
TABLE II.

Energy Difference, in $\mathrm{kJ} / \mathrm{mol}$, between the Lowest Singlet State and the First Triplet One or That Related with the External Instability, at Several Calculation Levels.

\begin{tabular}{|c|c|c|c|}
\hline Molecular System (SG) (bs) & CaLe & $\Delta E$ & SySt \\
\hline \multicolumn{4}{|l|}{ Nonantiaromatic systems } \\
\hline \multirow[t]{2}{*}{ trans-Butadiene $\left(\mathrm{C}_{2 h}\right)\left(6-31 \mathrm{G}^{* *}\right)$} & HF & $165.2^{b}$ & ${ }^{3} \mathrm{~B}_{\mathrm{u}}$ \\
\hline & $\operatorname{CAS}(4,4)$ & $250.6^{b}$ & ${ }^{3} \mathrm{~B}_{\mathrm{u}}$ \\
\hline $\mathrm{BC}_{4} \mathrm{H}_{5}\left(\mathrm{C}_{2 \mathrm{v}}\right)\left(6-31 \mathrm{G}^{* *}\right)$ & $\mathrm{HF}$ & $147.6^{\mathrm{a}}$ & ${ }^{3} \mathrm{~B}_{2}$ \\
\hline \multirow[t]{2}{*}{ Cyclopropylium cation $\left(\mathrm{D}_{3 \mathrm{~h}}\right)\left(6-31 \mathrm{G}^{* *}\right)$} & $\mathrm{HF}$ & $656.8^{\mathrm{a}}$ & ${ }^{3} \mathrm{E}^{\prime}$ \\
\hline & $\operatorname{CAS}(2,3)$ & $637.5^{\mathrm{b}}$ & ${ }^{3} \mathrm{E}^{\prime}$ \\
\hline \multirow{2}{*}{ Cyclopentadienyl anion $\left(D_{5 h}\right)\left(6-31+G^{* *}\right)$} & $\operatorname{PP}-\mathrm{CAS}(6,8)$ & $416.9^{b}$ & ${ }^{3} \mathrm{E}_{1}^{\prime}(\mathrm{PP})(\mathrm{c})$ \\
\hline & PS-CAS $(6,8)$ & $304.7^{\mathrm{b}}$ & ${ }^{3} E_{1}^{\prime \prime}(P S)$ \\
\hline \multirow{2}{*}{ Imidazole $\left(\mathrm{C}_{\mathrm{s}}\right)\left(6-31 \mathrm{G}^{* *}\right)$} & HF & $367.4^{\mathrm{a}}$ & ${ }^{3} \mathrm{~A}^{\prime}$ \\
\hline & $\operatorname{CAS}(6,6)$ & $375.6^{b}$ & ${ }^{3} A^{\prime}$ \\
\hline \multirow[t]{2}{*}{ Pyrrole $\left(\mathrm{C}_{2 \mathrm{v}}\right)\left(6-31 \mathrm{G}^{* *}\right)$} & $\mathrm{HF}$ & $290.7^{b}$ & ${ }^{3} \mathrm{~B}_{2}$ \\
\hline & $\mathrm{CAS}(6,6)$ & $361.3^{b}$ & ${ }^{3} \mathrm{~B}_{2}$ \\
\hline Benzene $\left(D_{6 h}\right)\left(6-31 G^{* *}\right)$ & $\operatorname{CAS}(6,6)$ & $355.5^{b}$ & ${ }^{3} \mathrm{~B}_{14}$ \\
\hline \multirow{3}{*}{$\mathrm{BC}_{5} \mathrm{H}_{6}^{-}\left(\mathrm{C}_{2 \mathrm{v}}\right)\left(6-31+\mathrm{G}^{* *}\right)$} & $\mathrm{CAS}(6,8)$ & $263.6^{a}$ & ${ }^{3} \mathrm{~B}_{1}(\mathrm{PS})(\mathrm{c})$ \\
\hline & & $284.1^{\mathrm{a}}$ & ${ }^{3} \mathrm{~A}_{2}$ (PS) \\
\hline & & $303.3^{\mathrm{a}}$ & ${ }^{3} A_{1}(P P)$ \\
\hline \multirow{2}{*}{$\mathrm{N}_{6} \mathrm{H}_{2}^{2+}\left(\mathrm{C}_{\mathrm{s}}\right)(6-31 \mathrm{G})$} & $\operatorname{CAS}(8,8)$ & $314.8^{\mathrm{a}}$ & ${ }^{3} A^{\prime \prime}(S P)(c)$ \\
\hline & & $419.0^{\mathrm{a}}$ & ${ }^{3} A^{\prime}(P P)$ \\
\hline \multirow[t]{2}{*}{ Cotp2 $\left(D_{8 h}\right)\left(6-31 G^{* *}\right)$} & $\mathrm{CAS}(6.8)$ & $273.2^{b}$ & ${ }^{3} E_{14}$ \\
\hline & & $290.4^{b}$ & ${ }^{3} E_{3 u}$ \\
\hline Anthracene $\left(D_{2 h}\right)(6-31 G)$ & $\mathrm{HF}$ & $206.9^{\mathrm{a}}$ & ${ }^{3} \mathrm{~B}_{1 \mathrm{u}}$ \\
\hline Phenanthrene $\left(C_{2 v}\right)(6-31 G)$ & $\mathrm{HF}$ & $234.3^{\mathrm{a}}$ & ${ }^{3} \mathrm{~B}_{2}$ \\
\hline \multirow{2}{*}{ An10 $\left(D_{10 h}\right)(6-31 G)$} & $\mathrm{HF}$ & $147.0^{\mathrm{a}}$ & ${ }^{3} B_{1 u}$ \\
\hline & $\operatorname{CAS}(10,10)$ & $204.7^{\mathrm{b}}$ & ${ }^{3} B_{1 u}$ \\
\hline Naphtacene $\left(D_{2 h}\right)(6-31 G)$ & $\mathrm{HF}$ & $130.3^{\mathrm{a}}$ & ${ }^{3} \mathrm{~B}_{1 \mathrm{u}}$ \\
\hline \multicolumn{4}{|l|}{ Antiaromatic systems } \\
\hline $\mathrm{C}_{3} \mathrm{H}_{3}^{-}\left(\mathrm{D}_{3 h}\right)\left(6-31+\mathrm{G}^{* *}\right)$ & $\operatorname{CAS}(4,7)$ & $-56.2^{\mathrm{a}}$ & ${ }^{3} \mathrm{~A}_{2}^{\prime}$ \\
\hline \multirow{3}{*}{ Cyclobutadiene $\left(\mathrm{D}_{4 \mathrm{~h}}\right)\left(6-31 \mathrm{G}^{* *}\right)$} & UHF(alt)(sg) \& UHF(tr) & $-128.7^{a}$ & ${ }^{3} A_{2 g}^{2}$ \\
\hline & $U H F($ reop) $(\mathrm{sg}) \& U H F(t r)$ & $102.9^{\mathrm{a}}$ & ${ }^{3} A_{2 g}$ \\
\hline & $\operatorname{CAS}(4,4)$ & $44.6^{\mathrm{b}}$ & ${ }^{3} \mathrm{~A}_{2 g}$ \\
\hline $\mathrm{C}_{5} \mathrm{H}_{5}^{+}\left(\mathrm{D}_{5 h}\right)\left(6-31 \mathrm{G}^{* *}\right)$ & $\operatorname{CAS}(4,5)$ & $-67.7^{a}$ & ${ }^{3} \mathrm{~A}_{2}^{\prime}$ \\
\hline \multirow{4}{*}{ Benzene dication $\left(D_{6 h}\right)(6-31 G * *)$} & UHF(alt)(sg) \& UHF(tr) & $34.4^{\mathrm{b}}$ & ${ }^{3} A_{2 g}^{2}$ \\
\hline & UHF(reop)(sg) \& UHF(tr) & $35.1^{\mathrm{b}}$ & ${ }^{3} \mathrm{~A}_{2 g}$ \\
\hline & $\operatorname{CAS}(4,6)$ & $-58.1^{b}$ & ${ }^{3} A_{2 q}$ \\
\hline & MP2/CAS(4.6) & $-48.6^{\mathrm{b}}$ & ${ }^{3} \mathrm{~A}_{2 g}$ \\
\hline
\end{tabular}

$\left(\mathrm{C}_{2 \mathrm{~h}}\right)$ within the 6-31G** basis set. At the CIS level, the ${ }^{3} \mathrm{~B}_{\mathrm{u}}$ state lies at $274.4 \mathrm{~kJ} / \mathrm{mol}$ (Table I) from the ground state, while the ${ }^{1} \mathrm{~B}_{\mathrm{u}}$ lies at $674.7 \mathrm{~kJ} / \mathrm{mol}$. At the better calculation level CAS $(4,4) / 6-31 \mathrm{G}^{* *}$, this ${ }^{1} \mathrm{~B}_{\mathrm{u}}$ is not the first excited singlet state because its energy relative to the ground state is $832.2 \mathrm{~kJ} / \mathrm{mol}$ compared with 644.5 for the ${ }^{1} \mathrm{~A}_{\mathrm{g}}$ (Table III) corresponding to another $\pi \rightarrow \pi^{*}$ excitation. This ${ }^{1} \mathrm{Ag}_{\mathrm{g}}$ state is found at $905.4 \mathrm{~kJ} / \mathrm{mol}$ at the CIS level. This is not typical of trans-butadiene alone, because pyrrole $\left(C_{2 v}\right)$, for instance, presents similar features. This can be understood from the RPA expressions, ${ }^{25}$ because the singlet transition matrix elements involve more bielectronic integrals, and are thus always larger than the triplet ones.

In a few cases the instability was not related with the first triplet state but with one higher triplet state $\left(1,2,3\right.$ triazine, $\left.\mathrm{N}_{6} \mathrm{H}_{2}^{2+}, \mathrm{N}_{6} \mathrm{H}_{4}^{4+}, \mathrm{C}_{6} \mathrm{H}_{6} \mathrm{~N}^{+}\right)$or with several $\left[\mathrm{N}_{6} \mathrm{H}_{4}^{4+}, \operatorname{An} 11 \mathrm{p} 1\left(\mathrm{C}_{1}\right)\right.$, An12p2 $\left(\mathrm{C}_{1}\right)$, naphtacene $\left(D_{2 h}\right)$, An14, pentacene $\left(D_{2 h}\right)$, An18, hexacene $\left(D_{2 h}\right)$, hexaphene $\left.\left(C_{s}\right)\right]$. In the former cases, the lower excited states result from $\sigma \rightarrow \pi^{*}$ transitions. 
TABLE II.

(Continued)

\begin{tabular}{|c|c|c|c|}
\hline Molecular System (SG) (bs) & CaLe & $\Delta E$ & SySt \\
\hline $\mathrm{C}_{7} \mathrm{H}_{7}^{-}\left(\mathrm{D}_{7 \mathrm{~h}}\right)\left(6-31+\mathrm{G}^{* *}\right)$ & CAS(8.8) & $-2.1^{\mathrm{a}}$ & ${ }^{3} \mathrm{~A}_{2}^{\prime}$ \\
\hline \multirow[t]{3}{*}{$\operatorname{Cot}\left(D_{8 h}\right)\left(6-31 G^{* * *}\right)$} & $U H F($ alt) (sg) \& UHF(tr) & $-17.1^{a}$ & \\
\hline & $U H F(r e o p)(s g) \& U H F(t r)$ & $190.7^{\mathrm{a}}$ & ${ }^{3} A_{2 g}$ \\
\hline & $\operatorname{CAS}(8,8)$ & $66.0^{\mathrm{b}}$ & ${ }^{3} \mathrm{~A}_{2 q}$ \\
\hline \multirow[t]{2}{*}{ An10p2 $\left(D_{10 h}\right)(6-31 G)$} & $\mathrm{UHF}(\mathrm{reop})(\mathrm{sg}) \& \mathrm{UHF}(\mathrm{tr})$ & $136.5^{\mathrm{b}}$ & ${ }^{3} \mathrm{~A}_{2}$ \\
\hline & $\operatorname{CAS}(8,10)$ & $-24.2^{b}$ & ${ }^{3} \mathrm{~A}$ \\
\hline \multirow[t]{5}{*}{ An12 (D $\left.D_{12 h}\right)(6-31 G)$} & $\mathrm{CAS}(12,9)$ & $25.7^{b}$ & ${ }^{3} \mathrm{~A}_{2 g}$ \\
\hline & $\operatorname{CAS}(10,10)$ & $66.1^{\mathrm{b}}$ & ${ }^{3} A_{2 g}$ \\
\hline & & $284.4^{b}$ & ${ }^{3} E_{14}$ \\
\hline & $U H F(a l t)(s g) \& U H F(t r)$ & $13.2^{b}$ & ${ }^{3} \mathrm{~A}$ \\
\hline & UHF(reop)(sg\&tr) & $227.5^{\mathrm{b}}$ & 30 \\
\hline
\end{tabular}

The symmetry group (SG) is the same for the singlet (sg) and the triplet (tr), (bs) indicates the basis set used.

CaLe = calculation level; HF means usual Hartree-Fock level for both entities, i.e., RHF(sg) and UHF(tr); UHF(alt) = UHF level for the singlet where the last occupied $\beta \mathrm{m} . \mathrm{s}$.o. (initially the same as the last $\alpha$ one) was permuted with the first virtual one, leading to a diradical singlet; UHF(reop) = UHF level for the singlet where the RHF wave function, found unstable, is reoptimized; SySt = symmetry of the triplet state: $\Delta E=E$ (triplet) $-E$ (singlet).

a Vertical triplet excitation energy.

b Triplet excitation energy at the optimized geometry of the first triplet state, within the SG restraints.

cThe triplet state results from a $\sigma \rightarrow \pi^{*}(\mathrm{SP})$ or a $\pi \rightarrow \sigma^{*}$ (PS) transition, instead of a $\pi \rightarrow \pi^{*}$ one (PP) (default). ${ }^{36}$

TABLE III.

Energy Differences between the Lowest Singlet States, in $\mathrm{kJ} / \mathrm{mol}$, at Several Calculation Levels.

\begin{tabular}{|c|c|c|c|}
\hline Molecular System (SG) (bs) & CaLe & $\Delta E$ & SySt \\
\hline \multicolumn{4}{|l|}{ Nonantiaromatic systems } \\
\hline trans-Butadiene $\left(\mathrm{C}_{2 h}\right)\left(6-31 \mathrm{G}^{* *}\right)$ & $\operatorname{CAS}(4,4)$ & 644.5 & ${ }^{1} A_{g}$ \\
\hline Imidazole $\left(\mathrm{C}_{\mathrm{s}}\right)\left(6-31 \mathrm{G}^{* *}\right)$ & $\operatorname{CAS}(6,6)$ & 658.6 & ${ }^{1} A^{\prime}$ \\
\hline Pyrrole $\left(\mathrm{C}_{2 \mathrm{~V}}\right)\left(6-31 \mathrm{G}^{* *}\right)$ & $\operatorname{CAS}(6,6)$ & 643.6 & ${ }^{1} A_{1}$ \\
\hline Benzene $\left(D_{6 h}\right)\left(6-31 G^{* *}\right)$ & $\operatorname{CAS}(6,6)$ & 470.6 & ${ }^{1} B_{1 u}$ \\
\hline \multirow{3}{*}{$\mathrm{N}_{6} \mathrm{H}_{2}^{2-}\left(\mathrm{C}_{5}\right)(6-31 \mathrm{G})$} & $\operatorname{CAS}(8,8)$ & 432.0 & ${ }^{1} A^{\prime \prime}(S P)^{a}$ \\
\hline & & 489.2 & ${ }^{1} A^{\prime \prime}(S P)$ \\
\hline & & 593.2 & ${ }^{1} \mathrm{~A}^{\prime}(\mathrm{PP})$ \\
\hline Cotp2 $\left(D_{8 h}\right)(6-31 G * *)$ & $\operatorname{CAS}(6,8)$ & 379.5 & ${ }^{1} E_{3 u}$ \\
\hline \multirow[t]{2}{*}{ An18 $\left(D_{18 h}\right)(6-31 G)$} & $\operatorname{CAS}(4,4)$ & 285.8 & ${ }^{1} \mathrm{~B}_{1 \mathrm{u}}$ \\
\hline & $\mathrm{CAS}(8,8)$ & 234.9 & ${ }^{1} \mathrm{~B}_{1 \mathrm{u}}$ \\
\hline \multicolumn{4}{|l|}{ Antiaromatic systems } \\
\hline $\mathrm{C}_{3} \mathrm{H}_{3}^{-}\left(\mathrm{D}_{3 \mathrm{~h}}\right)\left(6-31+\mathrm{G}^{* *}\right)$ & $\operatorname{CAS}(4,7)$ & 64.2 & ${ }^{1} A_{1}^{\prime}$ \\
\hline Cyclobutadiene $\left(\mathrm{D}_{4 h}\right)\left(6-31 \mathrm{G}^{* *}\right)$ & $\operatorname{CAS}(4,4)$ & 216.0 & ${ }^{1} A_{1 g}$ \\
\hline $\mathrm{C}_{5} \mathrm{H}_{5}^{-}\left(\mathrm{D}_{5 \mathrm{~h}}\right)\left(6-31 \mathrm{G}^{* *}\right)$ & $\operatorname{CAS}(4,5)$ & 74.8 & ${ }^{1} A_{1}^{\prime}$ \\
\hline Benzene dication $\left(D_{6 h}\right)\left(6-31 G^{* *}\right)$ & $\operatorname{CAS}(4,6)$ & 45.4 & ${ }^{1} A_{1 g}$ \\
\hline $\mathrm{C}_{7} \mathrm{H}_{7}^{-}\left(\mathrm{D}_{7 h}\right)\left(6-31+\mathrm{G}^{* *}\right)$ & $\operatorname{CAS}(8,8)$ & 35.4 & ${ }^{1} A_{1}^{\prime}$ \\
\hline $\operatorname{Cot}\left(D_{8 h}\right)\left(6-31 G^{* *}\right)$ & $\operatorname{CAS}(8,8)$ & 131.6 & ${ }^{1} A_{1 g}$ \\
\hline An10p2 ( $\left.D_{10 h}\right)(6-31 G)$ & $\operatorname{CAS}(8,10)$ & 18.0 & ${ }^{1} \mathrm{~A}_{1 \mathrm{~g}}$ \\
\hline \multirow[t]{2}{*}{ An12 $\left(D_{12 h}\right)(6-31 G)$} & $\operatorname{CAS}(12,9)$ & 65.6 & ${ }^{1} \mathrm{~A}_{1 \mathrm{~g}}$ \\
\hline & $\operatorname{CAS}(10,10)$ & 140.6 & ${ }^{1} A_{1 g}$ \\
\hline
\end{tabular}

(SG) Denotes the symmetry point group of the molecular system, (bs) indicates the basis set used.

CaLe $=$ calculation level; SySt $=$ symmetry of the excited singlet state; $\Delta E=E$ (excited singlet state) $-E$ (fundamental singlet state).

a The excited state results from a $\sigma \rightarrow \pi^{*}$ (SP) or a $\pi \rightarrow \sigma^{*}$ (PS) transition, instead of a $\pi \rightarrow \pi^{*}$ one (PP)/(default). 
In the latter cases, the mixing of several $\pi^{*}$ MOs, by the intermediate of several singly excited electronic configurations in the w.f. expansion, may be necessary to provide the optimized UHF w.f. with the best spin alternance related with the magnetically fully ordered state.

The importance of the perturbation leading to the reoptimized UHF w.f. is also related (Table I) with the value of $\left\langle S^{2}\right\rangle$ (reop), which can even become higher than the normal value for a triplet state (An14, naphtacene, An18, pentacene, hexacene, hexaphene). The greater the $\pi$ electron number, the greater the deviation to the singlet state description, which becomes highly contaminated by higher spin states. Nevertheless, the UHF energy is lower than the RHF one, although usually the contamination by the higher states provides a higher energy.

\section{RHF Internal Instability}

The internal HF instability, which occurs while remaining in the chosen HF (RHF or UHF) framework, is different from the external above mentionned one. It can often be directly related with the famous symmetry dilemma ${ }^{3,7}$ when the excited state of the same multiplicity has a different symmetry. As emphasized in a study on doublet states in ET processes, ${ }^{41}$ this HF instability involves nonadiabatic coupling, i.e., interaction between two electronic states that lie close to one another. This is what is found for An18 ( $\left.D_{18 h}\right)$, where the first excited singlet state, about $230 \mathrm{~kJ} / \mathrm{mol}$ above the ground ${ }^{1} \mathrm{~A}_{1 \mathrm{~g}}$ state, is $\mathrm{a}^{1} \mathrm{~B}_{1 \mathrm{u}}$. Thus, the reoptimized RHF w.f. no longer belongs to the $D_{18 \mathrm{~h}}$ symmetry point group because of the perturbation by the ${ }^{1} B_{1 u}$.

\section{Electronic Correlation}

Fourth-order perturbation Møller-Plesset ${ }^{34} \mathrm{cal}^{-}$ culations including single, double, and quadruple excitations [MP4(SDQ)] were performed on butadiyne (6-31G), trans-butadiene $(6-31 G)$, and benzene $\left(6-31 \mathrm{G}^{* *}\right)$, to estimate the electronic correlation importance obtained with the zero-order Slater determinant being either the RHF w.f, or the reoptimized UHF w.f. The results are shown in Table IV.

Though the (RHF $\rightarrow$ UHF) energy lowering $\Delta E$ (reop) lies around only -6.3 to $-11.3 \mathrm{~kJ} / \mathrm{mol}$ (results not all shown in Table I), the difference between the correlation energies obtained for the RHF and UHF w.f.s lies around +40 to $+80 \mathrm{~kJ} / \mathrm{mol}$. This largely lower correlation energy on the UHF w.f. emphasizes that this calculation level already takes into account an appreciable amount of the electronic correlation. This has to be put in relation with the appearance of non zero ASDs, i.e., with a certain degree of electronic localization that was precisely linked ${ }^{35 c}$ to the electronic correlation.

\section{HF INSTABILITY VS. THE NATURE OF THE SYSTEMS AND THE $\pi$ ELECTRONS NUMBER}

As recalled in a previous section, the optimum geometry results from an equilibrium between the $\pi$ "distortive" and $\sigma$ "antidistortive" electronic forces, ${ }^{35}$ nevertheless, the $\pi$ electrons conserve the possibility of delocalizing over the backbone. This is directly related to the quantum mechanical resonance energy (QMRE), a concept introduced by Coulson et al., ${ }^{42}$ and widely used. For annulenes $X_{n}$, it was shown $n^{35 a}$ that the distortive energy of the $\pi$ electrons was proportional to the triplet excitation energy of the $\mathrm{X}_{2} \pi$ bond $E_{\mathrm{tr}}\left(\mathrm{X}_{2}\right)$ : the higher this energy, the higher the $\pi$ electrons distortive energy to bring a single-double-bond alternance. Moreover, the localizing propensity of the $\pi$ electrons is related to their correlation: ${ }^{35 \mathrm{c}}$ the larger the $\pi$ electronic correlation, the higher their tendency to localize each around one nuclear center.

\section{Nonantiaromatic Systems}

Geometry Optimization with the UHF Reoptimized w.f. A further geometry optimization was performed with the UHF reoptimized w.f., for transbutadiene $(6-31 \mathrm{G})$, butadiyne $\left(6-31 \mathrm{G}, 6-31 \mathrm{G}^{* *}\right)$, ful-

TABLE IV.

Correlation Energies (kJ/mol) $E_{\mathrm{Rcorr}}=E(\mathrm{RMPx})-E(\mathrm{RHF})$ and $E_{\text {Ucorrx }}=E(\mathrm{UMPx})-E(\mathrm{UHF}), \mathrm{x}=2$ and 4 , Obtained in the RHF or the Reoptimized UHF Framework, for Butadiyne, trans-Butadiene, and Benzene.

\begin{tabular}{lllrrr}
\hline Molecule & Basis set & $E_{\text {Rcorr2 }}$ & $E_{\text {Ucorr2 }}$ & $E_{\text {Rcorr4 }}$ & $E_{\text {Ucorr4 }}$ \\
\hline Butadiyne & $6-31 G$ & -924.7 & -833.0 & -965.2 & -908.5 \\
trans-Butadiene & $6-31 G$ & -916.3 & -846.6 & -1021.1 & -965.2 \\
Benzene & $6-31 G^{* *}$ & -2076.0 & -1993.6 & -2172.5 & -2127.5 \\
\hline
\end{tabular}


vene $\left(6-31 G^{* *}\right)$, benzene $\left(6-31 G^{* *}\right)$, naphtalene (6$31 G)$, anthracene (6-31G), and phenanthrene (6$31 G)$. The critical point obtained was always a minimum, as controlled by analytical frequency calculations, in the same symmetry point group as the initial one, except for fulvene, though the MOs did no longer belong to that symmetry. The benzene $\mathrm{C}-\mathrm{C}$ bonds turned to be $0.00095 \mathrm{~nm}$ larger, the unsaturated bonds in butadiyne and butadiene also increased $\left[\delta(C \equiv C)=0.00159 \mathrm{~nm}\right.$ in $6-31 \mathrm{G}^{* *}$ and $0.00334 \mathrm{~nm}$ in $6-31 \mathrm{G}$, and $\delta(\mathrm{C}=\mathrm{C})=0.00356 \mathrm{~nm}$, while the central $\mathrm{C}-\mathrm{C}$ bond decreased to a smaller extent $[\delta(C-C)=-0.00140 \mathrm{~nm},-0.00248 \mathrm{~nm}$, in 6 $31 \mathrm{G}^{* *}$ and $6-31 \mathrm{G}$, respectively, for butadiyne, and $-0.00257 \mathrm{~nm}$ for butadiene]. The $\mathrm{C}-\mathrm{H}$ bonds were much less sensitive to the geometry reoptimization. The fact that the initially smaller bond lengths increase and that the larger ones decrease upon geometry optimization with the reoptimized UHF w.f. is also observed for naphtalene, anthracene, and phenanthrene, the systems thus tending to less pronounced single/double bond alternance. If one refers to previous works on $\sigma-\pi$ electron trends, this should mean that the reoptimized UHF w.f. provides a description of the $\pi$ electrons possessing less distortive tendency. Moreover, the inclusion of electronic correlation provides a smaller single/double bond difference, as observed for trans-butadiene at the MP2 level: $\mathrm{C}-\mathrm{C}$ and $\mathrm{C}=\mathrm{C}$ bond lengths pass from 0.14672 and $0.13221 \mathrm{~nm}$ at the RHF level to 0.14567 and $0.13431 \mathrm{~nm}$ at the MP2 one. The reoptimization of the HF w.f. takes into account a part of the electronic correlation.

The case of fulvene is somewhat different. The fully optimized geometry obtained with the reoptimized UHF w.f. belongs to the $C_{s}$ point group, the difference with $C_{2 v}$ being significant and mostly visible on the saturated $\mathrm{C}-\mathrm{C}$ bond lengths with the ethylenic extremity; from the initial $C_{2 v}$ values of $0.14770 \mathrm{~nm}$, they become equal to 0.14494 and $0.14961 \mathrm{~nm}$ in $\mathrm{C}_{\mathrm{s}}$. The bond lengths and ASDs on the carbons are presented in Chart 2.

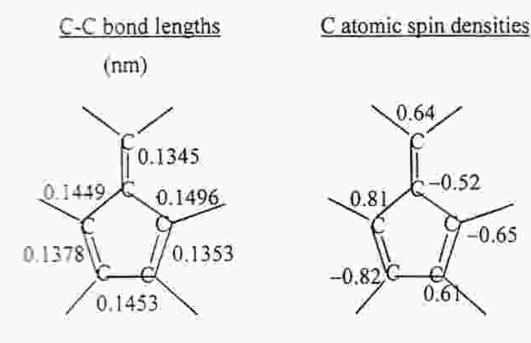

CHART 2.
The comparison of fulvene and benzene shows that the HF instability is very similar in both systems, but the geometry reoptimization with the reoptimized UHF w.f. produces quite different results. As a matter of fact, for benzene, only a spin alternance results from the reoptimization of the w.f., and it does not perturb the global symmetry because this alternance is already a characteristics of this system. In contradistinction, fulvene is a nonalternant hydrocarbon, and the magnetically reordered spins cannot result in a regular alternant scheme. As seen from Chart 2, a triplet coupling appears between the atomic centers linked through the larger bond length at the UHF-optimized geometry.

Systems with Two $\pi$ Electrons. In the case of such a small number of $\pi$ electrons (ethylene, cyclopropene, truncated cephalosporine), the instability is very small within the $6-31 \mathrm{G}$ basis set and disappears with the $6-31 \mathrm{G}^{* *}$ or $6-31+\mathrm{G}^{*}$ ones. The cyclic tension does not seem to perturb the instability.

Systems with Four $\pi$ Electrons. The planarity of the system does influence the importance of the instability, by comparison of trans (or cis) and twisted butadiene. The $\pi$ electronic correlation is larger when the system is planar, due to the better overlapping between the $\mathrm{p}_{z}$ atomic orbitals on which the $\pi \mathrm{MO}$ are expanded. As already recalled, the larger this electronic correlation, the more important the localization trend of the $\pi$ electrons on each nuclear site. ${ }^{35 \mathrm{c}}$ The electronic localization manifests itself, namely, via the ASDs derived from the reoptimized UHF w.f.: they are equal to -0.62 and +0.58 a.u. $\left(\mathrm{e} / \mathrm{bohr}^{3}\right)$ for the two distinct carbons of trans-butadiene, and to -0.52 and +0.51 a.u. in the case of twisted butadiene. Such an observation could lead one to suppose the existence of a relation between the electronic $\pi$ correlation and the HF instability: the higher the correlation, the higher the HF instability.

The presence of the boron in the five-membered ring $\mathrm{BC}_{4} \mathrm{H}_{5}$ highly increases the instability. The comparison of three of its properties (atomic net charges, ASDs, and difference in $\mathrm{C}-\mathrm{C}$ bond lengths) with those of cis-butadiene is presented in Table V.

The presence of the boron induces (i) a greater bond length difference, exclusively due to the lengthening of the $\mathrm{C}_{\text {int }}-\mathrm{C}_{\text {int }}$ bond; (ii) a larger negative net charge on its adjacent carbons, $\mathrm{C}_{\text {ext; }}$ (iii) a larger ASD of the UHF reoptimized w.f. on the carbons, meaning a stronger localization of the $\pi$ electrons, and thus, a larger electronic correlation. 
TABLE V.

Net Charges (NC) from the Mulliken Population Analysis, on the Carbons Linked to the Heteroatom $\left(\mathrm{C}_{\text {ext }}\right)$ and the Carbons Linked to Two Other Carbons $\left(C_{i n t}\right)$ in the Case in the Five-Membered Rings.

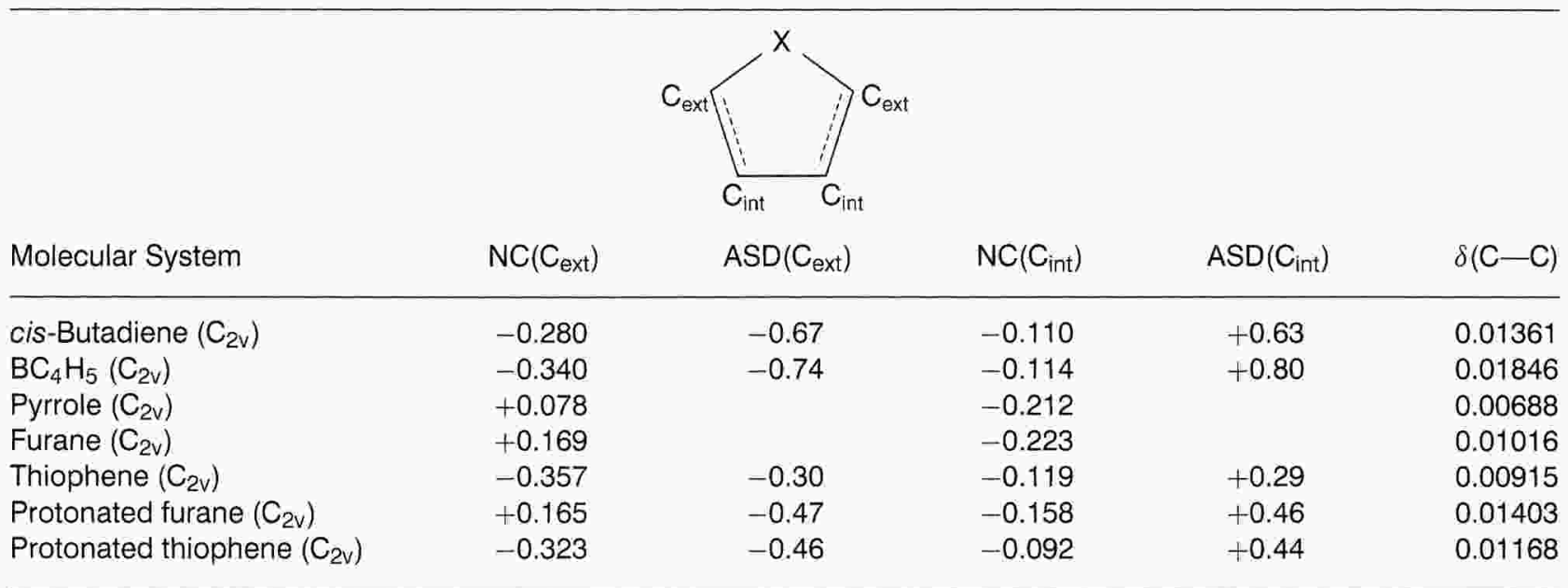

A comparison is made with the cis-bytadiene $\left(C_{2 v}, T S\right)$. The basis set used is $6-31 G^{* *}$. The difference between the larger $\left(C_{i n t}-C_{i n t}\right)$ and shorter $\left(\mathrm{C}_{\text {ext }}-\mathrm{C}_{\text {int }}\right)$ bond lengths is also presented: $\delta(\mathrm{C}-\mathrm{C})(\mathrm{nm})=\left(\mathrm{C}_{\mathrm{int}}-\mathrm{C}_{\mathrm{int}}\right)-\left(\mathrm{C}_{\text {ext }}-\mathrm{C}_{\text {int }}\right)$. The atomic spin densities (ASD) on the two carbons, obtained with the reoptimized UHF w.f., are given.

It seems that the presence of boron results in a restrained space for the $\pi$ electrons, probably linked with the geometry.

Systems with Six $\pi$ Electrons. Influence of the geometry: as already emphasized for four- $\pi$ electron systems, the planarity of the system influences the magnitude of the instability. The case of the hexatriene isomers clearly emphasizes this feature also.

The instability of hexatriene, whatever its conformation, is greater than that of benzene. For trans-E,E hexatriene, an additional geometry optimization was performed, at the $\mathrm{HF} / 6-31 \mathrm{G}^{* *}$ level, under the restraint that all the $\mathrm{C}-\mathrm{C}$ bond lengths are equal. This led to a structure that is not a critical point. The optimized bond length is $r_{\mathrm{C}-\mathrm{C}}(\mathrm{opt})=0.13737 \mathrm{~nm}$. This system has an even more unstable RHF w.f.: the $\Delta E$ (reop) is equal to $-68.915 \mathrm{~kJ} / \mathrm{mol}$. Thus, it is not the geometrical characteristics of the single/double bond alternance that produces larger instabilities compared with symmetrical systems like benzene. It should rather be an electronic feature related with electronic resonance. The two usual cyclic geometrical resonance forms for benzene leading to the well-known idea of electronic delocalization can be associated with two equivalent cyclic resonance forms for spin singlet coupling pattern, as shown is Chart 3.

Such coupling pattern resonance structures can be drawn for noncyclic species like hexatriene, but none of them should have a large weight because they are either diradicalar or zwitterionic; the double arrows must then show an equilibrium displacement towards one of the structures. Thus, it seems that the larger the resonance is, the lower is the triplet HF instability.

Influence of heteroatoms: for six- or sevenmembered rings, the replacement of one $\mathrm{C}-\mathrm{H}$ unit by one nitrogen (benzene $\rightarrow$ pyridine, $\mathrm{C}_{7} \mathrm{H}_{7}^{+} \rightarrow$ $\mathrm{C}_{6} \mathrm{H}_{6} \mathrm{~N}^{+}$) has nearly no influence on the instability, the "nitrogen $\pi$ electron" participating equally well to the appearance of the spin alternance. When more than one nitrogen replace $\mathrm{C}-\mathrm{H}$ units, their relative position in the ring is determinant in the way they
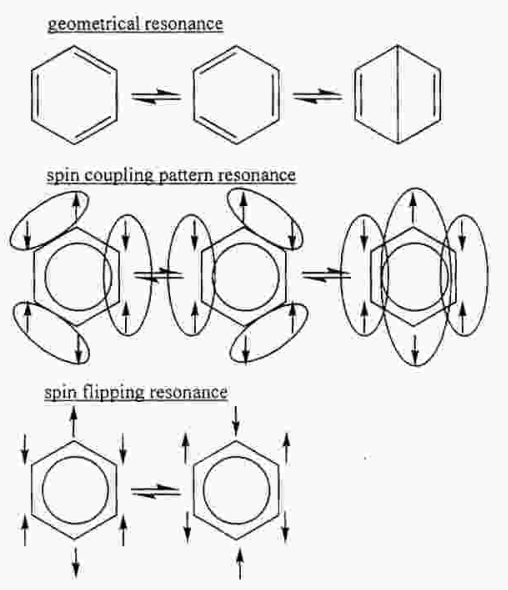

CHART 3. 
influence the instability. If they are connected altogether (pyridazine, 1,2,3 triazine, hexazine, $\mathrm{N}_{6} \mathrm{H}_{x}^{x+}$ ), the instability increases as a function of the nitrogen number. In this series, only hexazine ${ }^{43}$ is not a minimum but a TS. Its elusiveness was explained by Shaik et al. ${ }^{35 a}$ as coming from a $\pi$ distortive strength larger than the $\sigma$ symetrizing one. The reverse situation is observed when the nitrogens are separated by a carbon (pyrimidine, 1,3,5 triazine): the larger the number of nitrogens, the lower the instability. In the case of 1,3,5 triazine, the RHF w.f. is stable, the instability root being positive though very small: $\therefore(\operatorname{tr})=4.121 \mathrm{~kJ} / \mathrm{mol}$. The propensity to lead to a magnetically ordered lattice with alternating spins $\mathrm{s}^{40}$ seems to be stronger when identical atoms are not separated, at least when carbon and nitrogen are concerned.

The influence of the number and the position of the nitrogens in six-membered rings was investigated in the spin-coupled (SC) w.f. framework ${ }^{44}$ by Cooper et al. They calculated that the resonance energy was the same for benzene and pyridine- that it increased for pyrimidine and decreased for pyridazine. However, their definition of the resonance energy is not the usual one, ${ }^{35 a}$ they defined it as the energy difference between the full SC description and that corresponding to the most important spin coupling scheme, which is the Kekule form for all the studied structures. Given the geometry, the fact that the w.f. expands on important valence bond (VB) configurations other than the Kekule ones implies a large $\pi$ delocalization: the greater the number of non-Kekule configurations with large expansion coefficients, the larger the electronic delocalization. Thus, in this sense, pyrimidine is a more delocalized system than benzene, while pyridine is a less delocalized one. As already deduced from the hexatriene/benzene comparison, it appears that the more delocalized the $\pi$ system is, the lower is the HF instability. In contradistinction, entities like hexazine are $\pi$ localized systems that should present a large electronic correlation, ${ }^{35 c}$ in relation with the observed large HF instability.

The influence of nitrogen was also studied in seven membered rings. Chart 4 presents the way the single/double bond alternance appears in the geometry of the three systems $\mathrm{C}_{7} \mathrm{H}_{7}^{+}, \mathrm{NC}_{6} \mathrm{H}_{6}^{+}$, and $\mathrm{BC}_{6} \mathrm{H}_{7}$, as well as the ASDs on the heavy nuclei for the reoptimized w.f.

The high symmetry of $\mathrm{C}_{7} \mathrm{H}_{7}^{+}$, coming from the equilibrium between the $\sigma$ and $\pi$ electron trends, allows, as a by-product, an electronic resonance, just like benzene. This is no longer the case for nonsymmetrical species like $\mathrm{BC}_{6} \mathrm{H}_{7}$ and $\mathrm{NC}_{6} \mathrm{H}_{6}^{+}$. Nitrogen

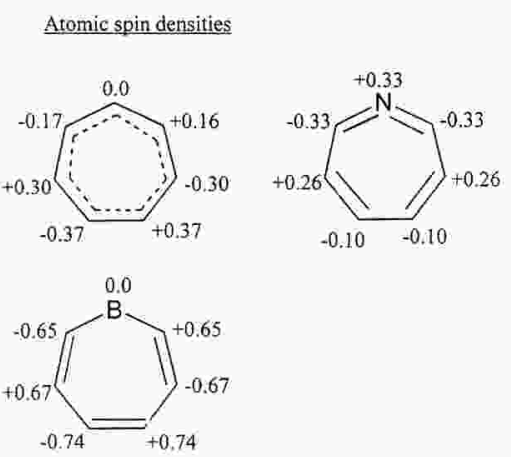

CHART 4.

has a propensity to easily form four bonds. In the case of $\mathrm{C}_{6} \mathrm{H}_{6} \mathrm{~N}^{+}$, according to the calculated bond lengths, $\mathrm{N}$ forms two double bonds with its two neighboring carbon atoms. This behavior produces, in return, a butadiene-like geometrical structure opposite to $\mathrm{N}$. The geometry of this system is not as symmetric as that of $\mathrm{C}_{7} \mathrm{H}_{7}^{+}$. However, the HF instability is very weak also. When looking at the ASDs of the UHF reoptimized w.f., one can understand that the degree of electronic localization is, on the average, of the same order as that in $\mathrm{C}_{7} \mathrm{H}_{7}^{+}$. Instead of a null ASD on one carbon, there are two ASDs of -0.10 on two adjacent carbons, indicating the delocalization of one $\pi$ eletron around these two nuclei. For the other ASDs values, they are of the same order, meaning a similar electronic localization degree, or conversely, a similar delocalization or resonance tendency, for the two systems.

The boron has the characteristic of increasing the instability in four of the cases studied. Its ASD remains null after the w.f. reoptimization. It only makes single $\mathrm{C}-\mathrm{B}$ bonds (Chart 4) and, in $\mathrm{BC}_{6} \mathrm{H}_{7}$, for instance, it compels the $\mathrm{C}_{6}$ backbone to form alternant single/double bonds as in hexatriene. Interestingly, the $\triangle E$ (reop) of hexatriene is very similar to that of $\mathrm{BC}_{6} \mathrm{H}_{7}$. From the reoptimized UHF w.f. ASDs values, it appears that the $\pi$ electrons are rather strongly localized. Thus, in seven-membered rings, the boron seems to act as a $\pi$ electron localizer, as in five-membered rings by the fact that it forces the geometry to be of single/double bond alternant type. This boron behavior as a "nonparticipant" to the $\pi$ delocalization is also very clear in the fact that the six-membered ring $\mathrm{BC}_{5} \mathrm{H}_{6}^{-}$has a stable RHF w.f. $\left(\lambda^{0}(\operatorname{tr})=+18.475 \mathrm{~kJ} / \mathrm{mol}\right)$, and has very similar characterictics as the five-membered ring Cpdm1 (low $\pi \rightarrow \sigma^{*}$ transitions, for instance). In the case of borazine, Cooper et al. ${ }^{45}$ emphasized, in the spin-coupled (SC) w.f. framework, that boron did not bear a specific optimized atomic orbital. The 
situation turns to be, electronically, as if boron was absent, although it strongly influences the geometry.

Number of $\pi$ sites: the number of nuclear sites also has an influence on the instability, the sevenmembered ring $\mathrm{C}_{7} \mathrm{H}_{7}^{+}$being the least unstable and the eight-membered one Cotp2 being the most unstable, benzene lying in between. All the systems having six $\pi$ electrons are characterized by five singlet coupling schemes. ${ }^{44}$ The relative weights of all these configurations determine the magnitude of the resonance energy as defined by Cooper et al. The larger the resonance energy, the larger the $\pi$ electronic delocalization, and the less distinguishable the atomic net spins become. On this basis, $\mathrm{C}_{7} \mathrm{H}_{7}^{+}$ should be the most aromatic system of the three mentioned above.

The comparison of pyrrole and pyridine, respectively characterized by a stable and unstable RHF w.f., can lead one to think that the nature, or the number, of the nitrogen electrons involved in the electronic delocalization is of primary importance. When two electrons are donated by the nitrogen, the HF w.f. is either stable or less unstable than when the nitrogen donates only one electron to the $\pi$ network. This is confirmed by the high stability of borazine, despite the presence of three borons: each of the three nitrogens puts two electrons in the $\pi$ network. The peculiar behavior of nitrogen in five-membered rings was already emphasized by Cooper et al. $^{46}$ within the SC w.f. framework. The SC description of borazine and boroxine by Cooper et al. ${ }^{45}$ brought to the fore the singlet coupling of electron pairs on the nitrogens and the oxygens, respectively. This is in complete opposition with the behavior of benzene ${ }^{44}$ where the SC orbitals are very localized on each carbon atom, an observation quite parallel with the spin alternance appearing in the reoptimized w.f.

Some of the five-membered rings are stable entities (pyrrole, imidazole, imidazolium, Cpdm1), furane being a limit case. Nevertheless, their first triplet state lies in the same energy range as that of benzene, which is unstable. Thus, if there is a qualitative link between the relative CIS energy of the triplet state and the existence of a triplet instability, the extrapolation to a quantitative level is not possible. For these systems, the number of $\pi$ electrons is higher than the number of nuclear centers. For the highly symmetrical species Cpdm1, a spin alternance is not imaginable. Thus, the only possibility is a complete delocalization of the spin density with a null atomic average. All the $\alpha$ and $\beta$ m.s.o. are the same, which corresponds to a perfect singlet pairing between all the $\pi$ electron cou- ples. However, for systems containing one $\mathrm{N}-\mathrm{H}$ group or one oxygen giving two electrons to the $\pi$ system, $\mathrm{N}$ and $\mathrm{O}$ can break in some way the complete delocalization of the whole $\pi$ cloud by imposing, in their environment, a singlet coupling of two electrons, as mentionned above. ${ }^{45}$ Thus, as far as the remaining $\omega$ electrons are concerned, the systems are very butadiene like, and should be unstable. Table V presents a comparison of some of their properties with the butadiene-related ones. Sulfur perturbs the least the electric charge distribution compared with cis-butadiene, although the central bond is rather affected. This geometrical difference become smaller when sulfur is protonated. The more the five-membered ring resembles cisbutadiene, the greater the HF instability. As a matter of fact, it is the only way to obtain a spin alternance in a five-membered ring with six $\pi$ electrons. Nevertheless, the question of the pyrrole and furan stability remains. It appears that, even if the two heteroatom $\pi$ electrons are singlet coupled, their presence strongly influences (15-20\% of the SC w.f. is not the Kekule form ${ }^{46}$ ) the $\pi$ delocalization. It seems that the furan $15 \%$ weight (or occupation number) of the non-Kekule VB configuration could be considered as a threshold for the appearance of the instability because thiophene, which has a RHF unstable w.f., is characterized by only $12 \%$ of the non-Kekule form in its SC w.f. ${ }^{46}$ Let us point out that furan and thiazole present the same occupation number for the most important VB configuration (R4), i.e., $85 \%$, while this number becomes equal to $88 \%$ for thiophene. Thus, furan and thiazole are more delocalized $\pi$ systems than thiophene, which has a more unstable RHF w.f. than the two formers. We, again, observe a correlation between the delocalization and the stability of the RHF w.f.

" $Y$ " $\pi$ systems: guanidine, guanidinium, and related species, often referred to as $Y$ aromatic systems, all present a stable RHF w.f. Obviously, two guanidine characteristics prevent the occurrence of a HF triplet instability. First, the number of nuclei that could bear a spin density is lower than the number of $\pi$ electrons, like in five-membered rings, in which a singlet pairing takes place when heteroatoms are present. Second, by reference to several nitrogen-containing species studied here, like pyrrole, the singlet coupling preferentially takes place on nitrogen rather than on carbon, thus leading to two guanidine nitrogens with singlet coupling, the third one being able to bear a spin density opposite to that on carbon. This possibility disappears for guanidinium where the three nitrogens are equivalent. A description in terms of a SC w.f. ${ }^{44-46}$ 


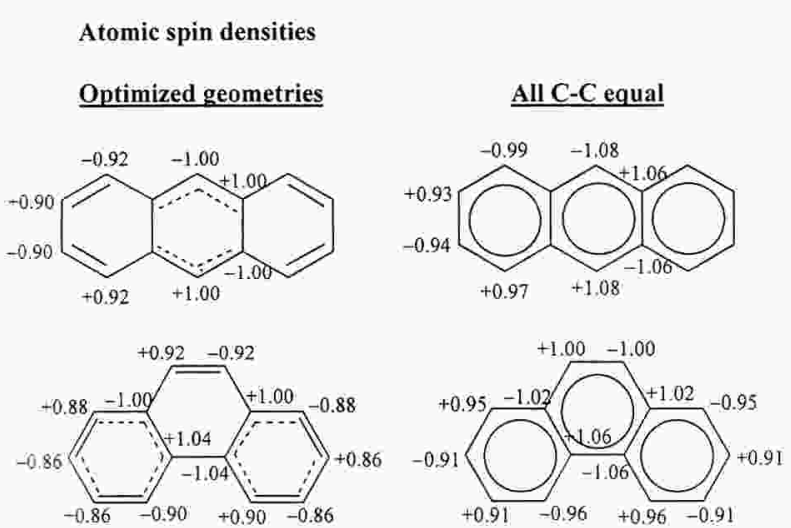

CHART 5.

and of delocalization indices ${ }^{35 c}$ would be very interesting for these systems because it seems that the delocalization is very peculiar.

Sustems with More Than $6 \pi$ Electrons. All the previous conclusions and remarks are confirmed by large systems.

(1) For a given number of electrons, and comparing planar systems in a local minimum, the instability is larger when the delocalization is smaller (cf, anthracene vs. phenanthrene, hexacene vs. hexaphene). Because the electronic $\pi$ delocalization is a by-product of the symmetrical geometry, this is shown schematically for anthracene and phenanthrene in Chart 5, by the representation of the single $(r>0.1425 \mathrm{~nm})$, double $(r<0.1375 \mathrm{~nm})$, and partially double $(0.1375 \mathrm{~nm}<r<0.1425 \mathrm{~nm})$ bonds. As a reminder, at the RHF / $6-31 G^{* *}$ level, the $\mathrm{C}-\mathrm{C}$ bond length in benzene is equal to $0.1386 \mathrm{~nm}$, and in hexatriene, the mean values for the three studied conformations are 0.1470 and $0.1327 \mathrm{~nm}$.

Thus, geometrically, phenanthrene is a less single /double alternant system than anthracene because the $\mathrm{C}-\mathrm{C}$ are not as different. As a matter of fact, the ASDs of the reoptimized UHF w.f. are smaller for phenanthrene than for anthracene. This is also true for geometries where all the $\mathrm{C}-\mathrm{C}$ bond lengths are equal. This points out the importance of the nuclear arrangement.

(2) When a nitrogen electron pair is involved in a cyclic polyene (indole), it breaks the delocalization by a singlet spin pairing of its two electrons (null spin density on $\mathrm{N}$ after the w.f. reoptimization). As a matter of fact, indole, with virtually $10 \pi$ electrons, has a $\Delta E$ (reop) similar to that of benzene.

Here above, it was pointed out that the planarity of the system was directly related with the $\Delta E$ (reop). This is confirmed by the comparison between naphtalene and An10 $\left(C_{2}\right)$, the latter being

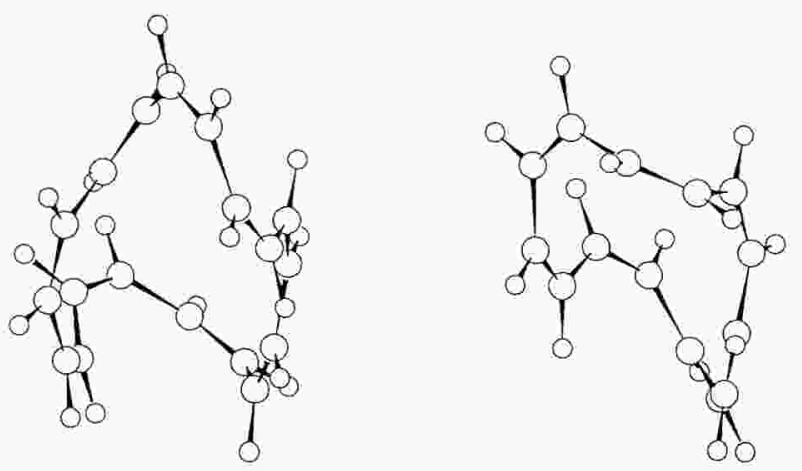

FIGURE 1. Optimized conformations of An14 $\left(\mathrm{C}_{1}\right)$ and An18 $\left(C_{1}\right)$, at the RHF/6-31G level.

not at all planar. ${ }^{38}$ By contrast, phenanthrene and An14 $\left(C_{1}\right)$ have very similar $\Delta E$ (reop) although one system is quite planar and the other is not at all (Fig. 1). Thus, several factors play a role in the importance of the HF instability, such as the planarity and delocalization or resonance scheme.

Isomeric comparisons: for the isomer pairs (anthracene, phenanthrene) and (hexacene, hexaphene), the relative energies were considerably changed when going from the RHF to the reoptimized UHF w.f. Within the RHF framework, the nonlinear molecules phenanthrene and hexaphene are much lower in energy than their related linear isomers: $\Delta E$ (phenanthrene-anthracene) $($ RHF $)=-31.895 \mathrm{~kJ} / \mathrm{mol}$ and $\Delta E$ (hexaphenehexacene) $($ RHF $)=-98.136 \mathrm{~kJ} / \mathrm{mol}$. These energy differences become much less important when considering the reoptimized UHF w.f.: $\Delta E$ (phenanthrene-anthracene) (UHF) $=-4.933$ $\mathrm{kJ} / \mathrm{mol}$ and $\Delta E$ (hexaphene-hexacene) $(\mathrm{UHF})=$ $-8.694 \mathrm{~kJ} / \mathrm{mol}$. This indicates that the correlation, leading to a certain degree of electronic localization, is much larger in anthracene and hexacene than in phenanthrene and hexaphene. Calculations at the MP levels should ascertain this hypothesis. At the MP2 and MP4 levels, considering a reduced set of MOs (from the 31st to the 66th) for generating the excited configurations and using the RHF w.f. (RMP2, RMP4) as zero-order reference, one obtains $\Delta E$ (phenanthrene-anthracene) $(\mathrm{RMP} 2)=-26.522$ $\mathrm{kJ} / \mathrm{mol}$ and $\Delta E$ (phenanthrene-anthracene) (RMP4) $=-21.995 \mathrm{~kJ} / \mathrm{mol}$. It appears that systems extending preferentially in one direction (1D) and looking like wires (anthracene, naphtacene, hexacene) have $\pi$ electrons that are much strongly correlated, and then localized, than systems that span over 2D space (phenanthrene, hexaphene).

For the nonplanar systems An10 $\left(C_{2}\right)$, An11p1 $\left(C_{1}\right)$, and An12p2 $\left(C_{1}\right)$, a small increase of the in- 
stability occurs when passing from An10 $\left(C_{2}\right)$ to An11p1 $\left(C_{1}\right)$, but the difference between An10 $\left(C_{2}\right)$ and An12p2 $\left(C_{1}\right)$ is much larger, and of the same order as the $\Delta E$ (reop) difference between benzene $\left(D_{6 h}\right)$ and Cotp2 $\left(D_{8 h}\right)$. The only common features of Cotp2 $\left(\mathrm{D}_{8 \mathrm{~h}}\right)$ and $\mathrm{An} 12 \mathrm{p} 2\left(\mathrm{C}_{1}\right)$ are their charge and the occurrence of two opposite null ASDs for the reoptimized w.f., thus dividing the cyclic backbone into two parts containing an odd number of nuclei.

\section{Antiaromatic Systems}

The antiaromatic systems are some kinds of diradicalar entities characterized by the fact that the two highest occupied MOs are degenerate and singly occupied. Thus, their energies cannot be determined at the RHF level, but at least at the UHF one (denoted as UHF(alt) in Table II). Consequently, the HF instability investigated is these systems is an internal one, because one remains in the UHF framework. The internal UHF instability of their w.f. was thus investigated, because Yamagushi ${ }^{40}$ found, within the INDO framework, that $\mathrm{C}_{3} \mathrm{H}_{3}^{-}, \mathrm{C}_{4} \mathrm{H}_{4}$, and $\mathrm{C}_{5} \mathrm{H}_{5}^{+}$do present a "spin-flipping" internal UHF instability. Internal UHF instabilities for some antiaromatic entities are presented in Table VI.

From these results, only the antiaromatic entities $\mathrm{C}_{4 n} \mathrm{H}_{4 n}$ present a large internal UHF instability, the other systems being either stable or very slightly unstable. The singlet lowest state of these $\mathrm{C}_{4 n} \mathrm{H}_{4 n}$ $\left(\mathrm{D}_{4 n \mathrm{~h}}\right)$ molecules is not a degenerate state, and is a critical point, i.e., its geometry is characterized by

TABLE VI.

\begin{tabular}{|c|c|c|c|}
\hline Molecular System (SG) & $\Delta E$ & $\left\langle S^{2}\right\rangle b$ & $\left\langle S^{2}\right\rangle a$ \\
\hline $\mathrm{C}_{3} \mathrm{H}_{3}^{-}\left(\mathrm{D}_{3 h}\right)$ & 0.0 & 1.06 & 1.06 \\
\hline Cyclobutadiene $\left(\mathrm{D}_{4 \mathrm{~h}}\right)$ & -231.7 & 00 & 1.25 \\
\hline $\mathrm{C}_{5} \mathrm{H}_{5}^{+}\left(\mathrm{D}_{5 \mathrm{~h}}\right)$ & -0.01 & 1.17 & 1.17 \\
\hline Benzene dication $\left(D_{6 h}\right)$ & -0.69 & 1.25 & 1.25 \\
\hline $\mathrm{C}_{7} \mathrm{H}_{7}^{-}\left(\mathrm{D}_{7 \mathrm{~h}}\right)$ & 0.0 & 1.25 & 1.25 \\
\hline $\operatorname{Cot}\left(D_{8 h}\right)$ & -207.5 & 1.08 & 1.63 \\
\hline $\mathrm{C}_{9} \mathrm{H}_{9}^{+}\left(\mathrm{D}_{9 h}\right)$ & -1.99 & 1.54 & 1.54 \\
\hline An10p2 ( $\left.\mathrm{D}_{10 h}\right)$ & 0.0 & 1.64 & 1.64 \\
\hline An12 (D $\left.D_{12 h}\right)$ & -279.6 & 1.15 & 2.27 \\
\hline An14p2 ( $\left.D_{14 h}\right)$ & 0.0 & 2.22 & 2.22 \\
\hline
\end{tabular}

The basis set used is the same as that for the CASSCF geometry optimization. $\Delta E=E(\mathrm{UHF}($ reop $))-E(\mathrm{UHF}) ;\left\langle S^{2}\right\rangle b$ and $\left\langle S^{2}\right\rangle$ a are the mean values of $S^{2}$ for the UHF w.f. before and after its reoptimization, in units of $\hbar$. a null gradient. In the case of cyclobutadiene and cyclooctatetraene (Cot), this point is a TS. ${ }^{47}$ For the ionic antiaromatics, this singlet is a degenerate state whose w.f. components, at the CASSCF level, can be represented by

$$
\begin{aligned}
& \psi^{(1)}=c_{1}\left[D_{1}-D_{2}\right]+\cdots \\
& \psi^{(2)}=c_{2}\left[D_{3}+D_{4}\right]+\cdots
\end{aligned}
$$

where the $\mathrm{D}_{i}$ are determinants for which the highest MO levels and their occupation numbers are represented in Chart 6. The MO pair components $\left(e_{x}^{(1)}\right.$, $\left.\mathrm{e}_{x}^{(2)}\right)$ are, respectively, the HOMO and the LUMO of the HF level. They are degenerate when both occupied, but they are no longer degenerate when one is doubly occupied and the other is virtual. Thus, four electronic configurations can be represented as $D_{1}, D_{2}, D_{3}$, and $D_{4}$ in Chart 6. At the CASSCF level, $D_{1}$ and $D_{2}$ are equivalent because the $M O$ pair $\left(\mathrm{e}_{x}^{(1)}, \mathrm{e}_{x}^{(2)}\right)$ is in the optimized active space, but this is not the case at the RHF level, where only one component is $\mathrm{SCF}$, the other being virtual. These two components have different symmetry properties, and the two RHF determinants $D_{1}$ and $D_{2}$ do not necessarily have the same energy. This is observed for the $\mathrm{C}_{4 n} \mathrm{H}_{4 n}$ antiaromatics, for which the RHF energy difference between $D_{1}$ and $D_{2}$ lie in the range of $21-34 \mathrm{~kJ} / \mathrm{mol}$. Nevertheless, for antiaromatic ions, $D_{1}$ and $D_{2}$ have the same RHF energy. This points out that, for these ions, the two molecular orbitals involved are actually equivalent, and
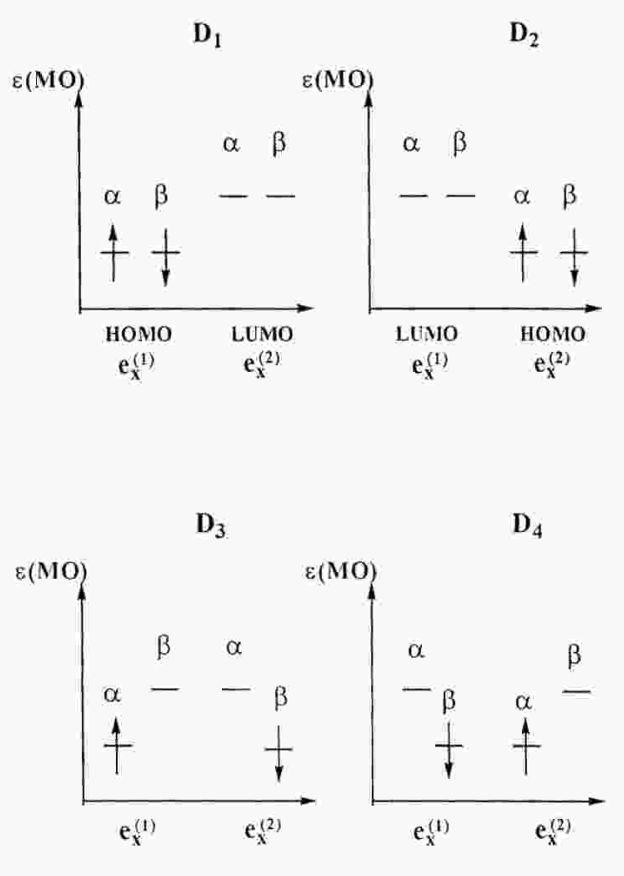

CHART 6. 
<smiles>[C]1[CH][CH]1</smiles>

LCAO coefficients on the $2 \mathrm{pz}$

before w.f. reoptimization

$\alpha$ HOSO<smiles>[C]1[CH][CH]1</smiles><smiles>[C]1[CH][CH]1</smiles>

$\beta \mathrm{HOSO}$

after w.f. reoptimization

$\alpha$ HOSO

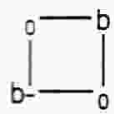

B HOSO
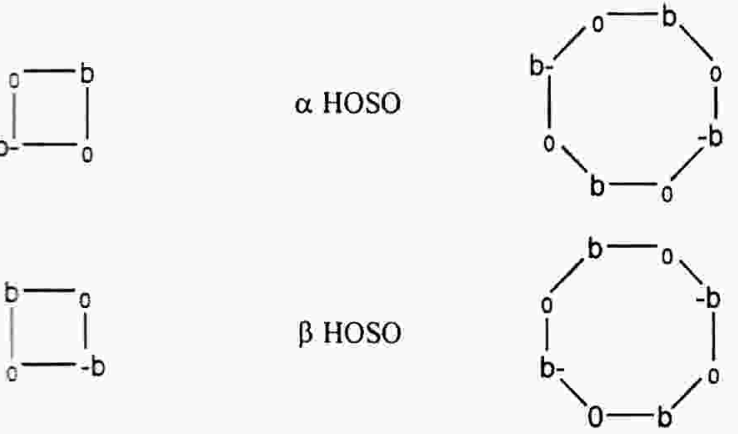

CHART 7.

any remixing between them could not change their energies, which are equal to the UHF energy of the diradicalar configurations $\mathrm{D}_{3}$ or $\mathrm{D}_{4}$. For the $\mathrm{C}_{4 n} \mathrm{H}_{4 n}$ species, the diradicalar singlet UHF w.f. obtained before and after reoptimization is characterized by the two highest occupied s.o. (HOSO) of the type shown in Chart 7.

There is a remixing leading to new HOSOs that do not involve common atomic centers, as already discussed by several authors. ${ }^{40,48,49}$ This transformation is accompanied by a large energy lowering, of about $210-290 \mathrm{~kJ} / \mathrm{mol}$, corresponding to a static correlation effect. Moreover, the ASDs, equal to zero on each atomic center before the w.f. reoptimization, become alternant, exactly as it is the case for benzene, each atomic center bearing alternatively a spin up or a spin down as represented below:<smiles>CC1CC2CC(I)C(I)C(I)C1C2</smiles><smiles>CC1C(I)C1C(I)I</smiles><smiles>CC1CCCC(I)C(C)CCC1C</smiles>

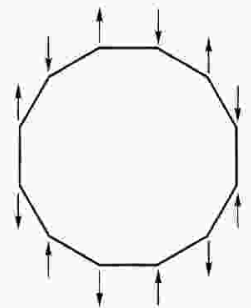

For the antiaromatic ions, the spin densities on the carbon atoms of the UHF w.f. before reoptimization (b.r.) and after (a.r.) are presented in Chart 8.

Let us point out that the UHF w.f., be it reoptimized or not, has not the symmetry of the geometry point group, in contradistinction of the INDO results by Yamagushi. ${ }^{40}$

The diradicalar character of the antiaromatic singlet state is apparent from the ASDs obtained either for the stable UHF w.f. of $\mathrm{C}_{3} \mathrm{H}_{3}^{-}, \mathrm{C}_{7} \mathrm{H}_{7}^{-}, \mathrm{An} 10 \mathrm{p} 2$, or for the nonreoptimized UHF w.f. of $\mathrm{C}_{5} \mathrm{H}_{5}^{+}$and benzene dication. It does not appear in the non reoptimized UHF w.f. of cyclobutadiene, Cot, or An12, because the spin densities on the carbons are null. However, this feature disappears in the reoptimized UHF w.f. spin densities of $\mathrm{C}_{4 n} \mathrm{H}_{4 n}, \mathrm{C}_{5} \mathrm{H}_{5}^{+}$, and benzene dication, where the spin pattern becomes completely or partially alternant. In the case of the antiaromatic anions, because the number of $\pi$ electrons is greater than the number of carbons, a completely alternant pattern is not possible. The case of $\mathrm{C}_{9} \mathrm{H}_{9}^{+}$presents a reversed situation because the best alternant spin scheme, without direct triplet couplings, is found in the nonreoptimized UHF w.f. A stable UHF w.f. with noncompletely alternant spins is also found for An10p2 and An14p2. As seen above, doubly charged nonantiaromatic annulenes have RHF w.f. more unstable than the uncharged system with the same number of $\pi$ electrons (comparing benzene with Cotp 2 and An10 with An12p2). The inverse is observed in the case of antiaromatic systems. This is one of the differences between external and internal HF instabilities. The RHF framework is not well suited to account for electronic localization leading to spin alternance, while UHF is.

The UHF w.f. of all the antiaromatic systems is highly spin contaminated (see the $\left\langle S^{2}\right\rangle$ values in Table VI), the value of 1 being equal to the exact average of the $S^{2}$ eigenvalues for a singlet and a triplet. This is to be related with the very proximity of the triplet state (Table II), in the $42-63 \mathrm{~kJ} / \mathrm{mol}$ range in most cases.

The singlet ground state of the $\mathrm{C}_{4 n} \mathrm{H}_{4 n}$ species, though characterized by the fact that the two last 

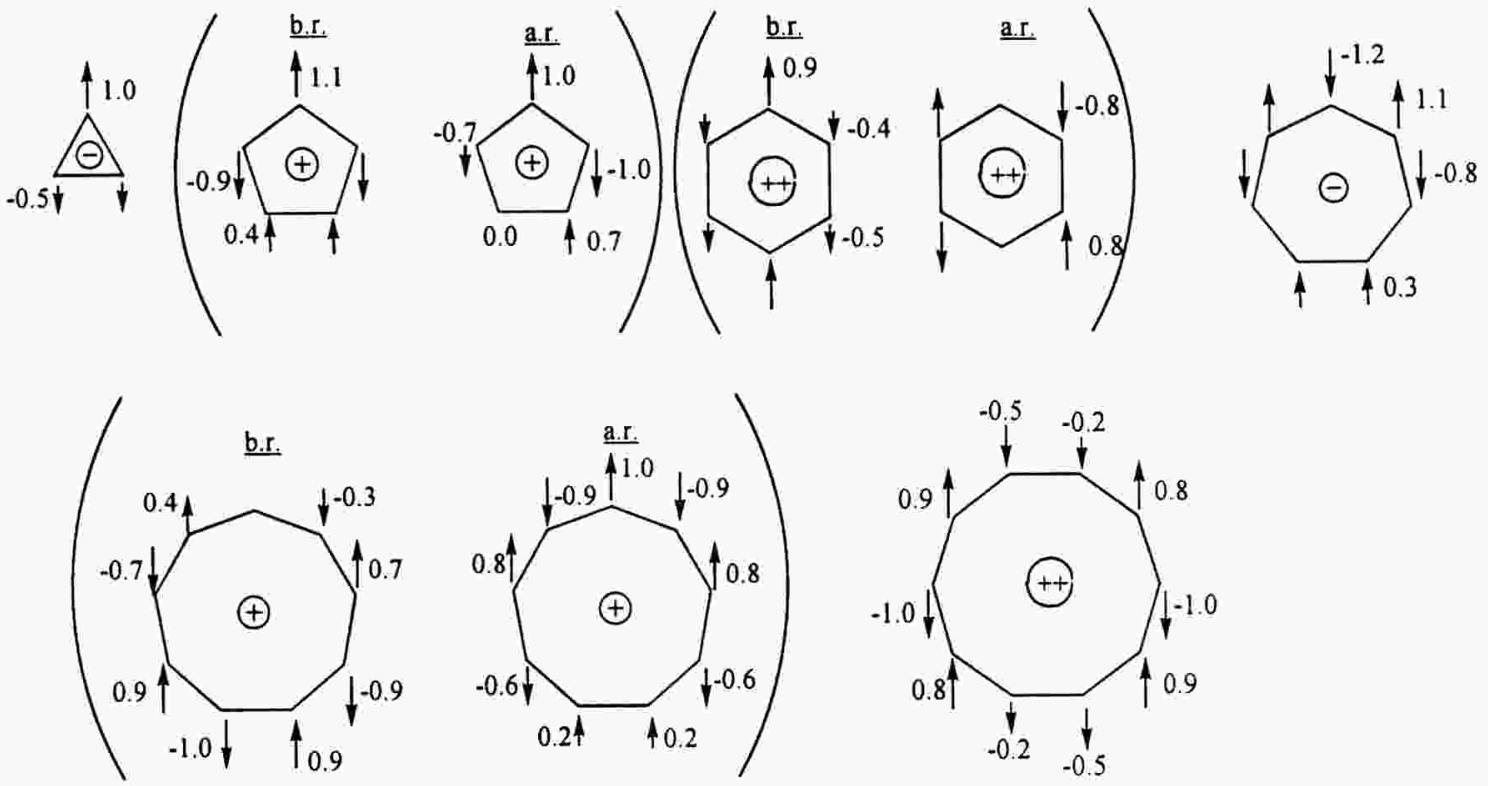

CHART 8.

valence electrons occupy two distinct degenerate $\mathrm{MOs}$, are not truly diradicalar entities, by contrast to the ionic antiaromatics. The internal HF instability occurring in ionic antiaromatics results in a simple rearrangement of the ASD alternance around the cycle, and this constitutes a little energetic effect. On the contrary, passing from null to alternating ASDs has a dramatic energetic effect. This type of spin distribution, quite similar to that of benzene, for instance, was already pointed out by Karadakov et al. ${ }^{50}$ within the SC w.f. theory.

In the case of the ionic antiaromatic systems, from the ASDs before and after the w.f. reoptimization (see above), the diradicalar character seems to decrease upon reoptimization. For the $\mathrm{C}_{4 n} \mathrm{H}_{4 n}$ systems, the w.f. reoptimization leads to a spin alternance like for the aromatics or the conjugate species, thus resembling more an external instability. However, the magnitude of $\Delta E$ (reop) is unusual, either for external instabilities (Table I) or the internal ones observed for doublet states, ${ }^{41}$ and mainly due to non adiabatic coupling. Thus, one can conclude that the static correlation effect mentionned above, leading to reoptimized $\mathrm{MOs}$ that are combinations of $\mathrm{AO}$ on noncommon nuclei, is the main energetic component of $\Delta E$ (reop).

The case of antiaromatic anions is particularly interesting. These systems are characterized by a number of $\pi$ electrons greater than the heavy nuclei number, just as the aromatic system Cpdm1. Consequently, by analogy, one should find null ASDs because there is no way to accommodate a spin al- ternance corresponding to all $\pi$ electrons. However, the observation is quite different, as seen in Chart 8 . The UHF w.f. of these species present a spin density that seems to imply one singlet pairing, the sum of the ASDs being about two units lower than the number of $\pi$ electrons. The analysis of the reoptimized $\alpha$ and $\beta$ m.s.o. LCAO expansion clearly shows that, in both cases of $\mathrm{C}_{3} \mathrm{H}_{3}^{-}$and $\mathrm{C}_{7} \mathrm{H}_{7}^{-}$, one $\alpha \pi$ m.s.o. is very similar to one $\pi \beta$, leading to a quasi-perfect singlet pairing between them and making them disappear from the spin density distribution, just like the case of Cpdm1.

Table II shows that, at the CASSCF level, some of the antiaromatic systems violates the multiplicity Hund's rule. ${ }^{51}$ This rule stipulates that, because of the degeneracy of the two highest occupied MOs, the triplet state should lie lower in energy than the singlet (meaning a negative $\Delta E$ ). This violation occurs for the annulenes $\mathrm{C}_{4 n} \mathrm{H}_{4 n}$, for which the triplet state lies higher than the singlet. The ionic antiaromatics obey the rule. This behavior was found by Yamagushi, ${ }^{40}$ Kollmar and Staemmler, ${ }^{48}$ and Gallup ${ }^{49}$ for fourfold symmetric systems, and related with the possibility of obtaining the last two degenerate orbitals built on nonadjacent centers, which provides a static correlation effect stabilizing the singlet. Moreover, they emphasized that the magnitude of the bielectronic integrals also plays a role in the rule violation. All these studies and conclusions were based on properties of the local $\mathrm{D}_{4 n \mathrm{~h}}$ point group. Nevertheless, a more nonlocal reasoning could be performed. For these $\mathrm{C}_{4 n} \mathrm{H}_{4 n}$ systems, 
there exist as many $\pi$ electrons as heavy nuclei; thus, one can easily imagine that a closed-shell representation would be preferred to a diradicalar one when a nondegenerate MO pair $\left(\mathrm{e}_{x}^{(1)}, \mathrm{e}_{x}^{(2)}\right)$ is concerned, i.e., when leaving the $\mathrm{D}_{4 n \mathrm{~h}} \mathrm{SG}$. This is not the case for the ionic antiaromatics that can equally accept both closed-shell and diradicalar representations, as seen from the two equivalent representations of the degenerate states (see above). Then, on a large variation domain of the internal coordinates of the $\mathrm{C}_{4 n} \mathrm{H}_{4 n}$ systems, these are "usual" closed-shell systems for which the triplet state is energetically higher than the singlet one. When arriving at the $\mathrm{D}_{4 n \mathrm{~h}}$ symmetry, there is no reason why they should abruptly have a triplet state lower than the singlet one; this would be an unphysical discontinuity.

For the antiaromatic ions, the correct relative triplet/singlet energy is obtained only at the CASSCF level (Table II). As a matter of fact, the singlet state is degenerate for all these species in their highest SG and HF calculations are not adequate. For the neutral antiaromatics $\mathrm{C}_{4 n} \mathrm{H}_{4 n}$, the reoptimization of the UHF singlet w.f. provides the correct ordering singlet/triplet, but the magnitude of the $\triangle E$ is too large compared with CASSCF results. The static electronic correlation correction in the reoptimized UHF w.f. is thus largely overestimated, due to a very poor zero-order UHF starting guess for such systems.

\section{RELATION WITH A SPIN-ORBIT COUPLING}

Most insaturated compounds present an external triplet instability. The MOs corresponding to the insaturation are expanded essentially on atomic basis functions of type $p$. These corresponds, in the atomic case, to atomic orbitals with nonnull orbital angular momentum $\mathbf{L}$, and are characterized by namely one nodal plane passing through the nucleus. In the absence of external field, the three $p$ atomic orbitals are degenerate. The threefold degeneracy reflects the three possible orientation of one $\mathrm{L}$ component along a chosen axis. In the molecular case, the threefold degeneracy related with the orbital angular momentum orientation is replaced by a $x$-fold degeneracy related with the symmetry properties of the monoelectronic MO functions. The $x$ value can become larger than two only in very high symmetry point groups (cubic, octahedral, icosahedral, ...) for which the threefold degeneracy of the usual 3D $(x, y, z)$ axes is restored. For linear or planar systems, one axis (the highest symmetry axis $z$ ) is usually favored, breaking down the latter threefold degeneracy. Then, the highest $x$ value is 2 , related with the so-called $\pi$ MOs, which all possess one nodal plane containing all the nuclei because they are expanded on $p$-like atomic basis functions. As an extension of the atomic case, and because the angular momentum is a constant of the motion if the spin is neglected, one would think that the twofold degeneracy of a MO is related with the angular momentum the system would have if this $\mathrm{MO}$ was singly occupied. In the more general case, where no symmetry exist but where insaturations are present, $x$ can only be equal to one, i.e., no degeneracy can be found except those purely accidental. Nevertheless, there exist MOs that are characterized, as $\pi$ ones in the planar case, by one nodal surface that passes through all the nuclei involved in the insaturations. Thus, they behave locally as $\pi$ MOs, and it is very temptating to associate an orbital angular momentum to the electrons that occupy these MOs. In turn, these electrons could be subject to a spin-orbit coupling, ${ }^{52}$ from the following reasoning. The UHF framework provides a w.f. that is no longer an eigenfunction of the $S^{2}$ operator. For many systems, the mean value of $S^{2}$ is equal to or very near its eigenvalue $S(S+1) \hbar^{2}$, $S$ being the total spin quantum number. However, for other systems like insaturated ones, relaxing the w.f. constraint to be an eigenfunction of $S^{2}$ by optimizing separately $\alpha$ and $\beta$ spin orbitals provides mean values of $S^{2}$ rather different from $S(S+1)$ a.u. In these cases, the system behaves as if the spin was no longer a "good" quantum number. This automatically implies that the spin angular momentum is coupled to another vectorial property such as the orbital angular momentum. Due to the relativistic origin of the spin, such interactions appear naturally in the relativistic expression of the Hamiltonian, in which all the energetic terms related with spin-orbit coupling are proportional to $\left(-g_{e} \mu_{B} \hbar^{2} /\left(2 m_{e}^{2} c^{2} r_{i j}^{3}\right)\right)\left(\mathbf{S}_{i} \cdot \mathbf{L}_{j}\right)$, where $g_{e}$ is the Lande factor (equal to 2.002319), $\mu_{B}$ is the Bohr magneton, $m_{e}$ is the electron mass, $c$ is the light speed, $r_{i j}$ is the distance between electrons $i$ and $j, \mathbf{S}_{i}$ is the spin angular momentum vector of electron $i$ (in a.u.), and $\mathbf{L}_{j}$ is the orbital angular momentum vector of electron $j$ (in a.u.). The factor $\left(-g_{e} \mu_{B} \hbar^{2} /\left(2 m_{e}^{2} c^{2} r_{i j}^{3}\right)\right)$ is equal to $2.666 \times 10^{-5}$ a.u., which corresponds to about $5 \mathrm{~cm}^{-1}$ if one takes $\left(\mathbf{S}_{i} \cdot \mathbf{L}_{i}\right)=1$. In closed-shell systems, all the terms should cancel out by electron pairing, giving rise to total angular momenta $\mathbf{L}, \mathbf{S}$, and $\mathbf{J}=\mathbf{L}+\mathrm{S}$ equal to zero. However, it could be imagined that, because of spin-orbit coupling, some individual components $\mathbf{S}_{i} \cdot \mathbf{L}_{j}$ are such as they remain after summation on all the electrons, resulting in nonzero $\mathbf{L}$ and $\mathrm{S}$ total vec- 
tors. This effect should be small, of the order of few tenths of a cm${ }^{-1}$, or a few $\mathrm{cm}^{-1}$ in the case of small molecules like benzene. But maybe is it sufficient to be in part responsible for the larger correlation found between the $\pi$ electrons in insaturated systems. This assumption could be seen as supported by the low-lying triplet state found in all the studied systems.

\section{Conclusions}

The existence of an external HF instability is obviously a characteristic of most unsaturated systems. Although qualitatively linked with the proximity of the excited $\pi^{*}$ levels, it is not quantitatively related with the excitation energy of the triplet state despite its denomination. It does concern, instead, the spin-coupling framework. The fact that it is a spinlinked property is already clear from the fact that the Fukutome classification ${ }^{11}$ results from properties of peculiar groups, the symmetry group consisting of spin rotation and time reversal. Moreover, it was shown that the $\pi$ electronic ensemble obey unusual bosonic intersite statistics under certain symmetry conditions. ${ }^{53}$ Consequently, it appears that the triplet HF instability is related with spin properties of systems that possess electrons with nonnull orbital angular momentum, typically $\pi$ electronic systems. The spin coupling pattern is maybe influenced by this orbital angular momentum, in which case one can speak of a spin-orbit coupling. If this is so, one can expect the occurrence of triplet HF instabilities in systems that do not present unsaturated sites as such, but that acquire, in a certain region of nuclear conformations, a nonnull orbital angular momentum.

A relation between the triplet $\mathrm{HF}$ instability and both the electronic correlation and the $\pi$ electrons resonance, or delocalization, was pointed out: the larger the electronic correlation, the larger the HF instability; the larger the resonance, the lower the HF instability.

The study of triplet HF instabilities emphasized the existence of an electronic correlation, and the related electronic localization, which is different for " $1 \mathrm{D}$ " condensed aromatic compounds like anthracene and " $2 \mathrm{D}$ " ones like phenanthrene.

Heteroatoms influence triplet instabilities either through the geometry that they impose (boron, sulfur), or through their chemical nature or, more probably, through both features (oxygen, nitrogen).

Antiaromatic systems are subject to internal UHF instabilities. These are rather small for ionic systems, while they are very large for neutral $\mathrm{C}_{4 n} \mathrm{H}_{4 n}$ molecules. This feature is related to an important static correlation effect.

\section{Appendix}

Here follows the list of the investigated molecular systems, within particular symmetry point groups (SG); when no SG is indicated, $S G$ is $C_{1}$. The calculation level for both the geometry optimization and the wave function stability study is also indicated for the antiaromatics, being otherwise the RHF one. The lowest level basis set used was 6-31G but, for several systems, one or two other basis sets were also used, including polarization or/and diffuse functions. When another basis set than 6-31G or more than one basis set was used, it is indicated in parentheses by (bs $n$ ), with $n$ as follows: $n=1$ : [6$\left.31 \mathrm{G}^{* *}\right] ; n=2:\left[6-31+\mathrm{G}^{* *}\right] ; n=3:\left[6-31 \mathrm{G}, 6-31 \mathrm{G}^{* * *}\right] ;$ $n=4:\left[6-31 \mathrm{G}, 6-31+\mathrm{G}^{*}\right] ; n=5:\left[6-31 \mathrm{G}, 6-31 \mathrm{G}^{* *}, 6-\right.$ $\left.31++\mathrm{G}^{* *}\right]$

The only system not optimized at the $a b$ initio level was a complex of 18 water molecules, optimized at the molecular mechanics (Amber) level. ${ }^{54}$ For antiaromatic systems, UHF(alt) means UHF level where the last $\beta$ spin-orbital from a RHF guess is permuted with the first $\beta$ virtual one, thus leading to a diradical singlet state; UHF(reop) means UHF level from a reoptimized wave function.

\section{ABBREVIATIONS}

$\mathrm{TS}=$ transition state; $\mathrm{Cpdm} 1=$ cyclopentadienyl anion; $\mathrm{C}_{5} \mathrm{H}_{6} \mathrm{NB}\left(\mathrm{t} 1, \mathrm{C}_{5}\right)=\mathrm{C}_{5} \mathrm{H}_{6} \mathrm{NB}\left(\mathrm{C}_{\mathrm{s}}\right)(\mathrm{N}$ and $\mathrm{B}$ separated by two carbon atoms); $\mathrm{C}_{5} \mathrm{H}_{6} \mathrm{NB}$ $\left(\mathrm{t} 2, \mathrm{C}_{\mathrm{s}}\right)=\mathrm{C}_{5} \mathrm{H}_{6} \mathrm{NB}\left(\mathrm{C}_{\mathrm{s}}\right)$ [N and $\mathrm{B}$ adjacent (TS)]; $\mathrm{C}_{5} \mathrm{H}_{6} \mathrm{NB}\left(\mathrm{t} 2, \mathrm{C}_{1}\right)=\mathrm{C}_{5} \mathrm{H}_{6} \mathrm{NB}\left(\mathrm{C}_{1}\right)$ ( $\mathrm{N}$ and $\mathrm{B}$ adjacent); $\mathrm{Cot}=$ cyclooctatetraene; $\operatorname{Cotp} 2=$ cyclooctatetraene dication; $A n 10=10$-annulene (or cyclodecatentaene); An10p2 = 10-annulene dication; An11p1 = 11-annulene monocation; An12 = 12-annulene (cyclododecahexaene); An12p2 = An12 dication; An14 = 14-annulene; An14p2 = 14-annulene dication; An18 = 18-annulene.

\section{FULLY SATURATED SYSTEMS}

Complex of 18 water molecules, cyclopropane ( $\left.\mathrm{D}_{3 \mathrm{~h}}\right)$, tertbutyl-methane, $\mathrm{NH}_{2} \mathrm{CH}_{3}, \mathrm{NH}_{2} \mathrm{BH}_{2}$, $\mathrm{BH}_{2} \mathrm{CH}_{3}$, cyclohexane.

\section{FULLY OR PARTIALLY UNSATURATED NONAROMATIC-LIKE SYSTEMS}

Dimethyl formamide, acetylene ( $\left.\mathrm{D}_{\infty \mathrm{h}}\right)$ (bs 3 ), ethylene $\left(D_{2 h}\right)$ (bs 3$)$, trans-butadiene $\left(C_{2 h}\right)$ (bs 3 ), 
twisted-butadiene $\left(\mathrm{C}_{2}\right)$ (bs 3), cis-butadiene (planeTS) $\left(C_{2 v}\right.$ ) (bs 3), butadiyne (bs 3 ), neutral arginine, side-chain protonated arginine, guanidine (bs 5), guanidinium (bs 5), methyl-guanidine (bs 5), truncated cephalosporine (bs 4), cyclopropene (bs 3), $\mathrm{BC}_{4} \mathrm{H}_{5}$ (5-membered ring) $\left(\mathrm{C}_{2 \mathrm{v}}\right)$ (bs 1 ), fulvene (bs 3), trans-e,e hexatriene $\left(\mathrm{C}_{2 h}\right)$ (bs 1$)$, cis-e,e hexatriene $\left(C_{2 v}\right)$ (bs 1$)$, cis-e, $z$ hexatriene (bs 1 ).

\section{UNSUBSTITUTED AROMATIC-LIKE SYSTEMS}

Cyclopropylium cation $\left(\mathrm{D}_{3 \mathrm{~h}}\right)$ (bs 1), cyclopentadienyl anion ( $\left.D_{5 \mathrm{~h}}\right)$ (bs 2$)$, pyrrole $\left(\mathrm{C}_{2 \mathrm{v}}\right)$ (bs 3 ), furane $\left(C_{2 v}\right)$ (bs 3), protonated furane $\left(C_{2 v}\right)$ (bs 3 ), imidazole $\left(\mathrm{C}_{\mathrm{s}}\right)$ (bs 3$)$, imidazolium cation $\left(\mathrm{C}_{\mathrm{s}}\right)$, thiophene $\left(C_{2 v}\right)$ (bs 1), protonated thiophene $\left(C_{2 v}\right)$ (bs 1$)$, thiazole (bs 3), benzene $\left(D_{6 \mathrm{~h}}\right)$ (bs 5), pyridine $\left(\mathrm{C}_{2 \mathrm{v}}\right)$ (bs 3$)$, pyrimidine $\left(\mathrm{C}_{\mathrm{s}}\right)$ (bs 3$)$, pyridazine $\left(\mathrm{C}_{2 \mathrm{v}}\right)$ (bs 1$)$, $1,2,3$ triazine $\left(C_{2 v}\right)$ (bs 1$), 1,3,5$ triazine $\left(D_{3 h}\right)$ (bs 1$)$, $\mathrm{BC}_{5} \mathrm{H}_{6}^{-}\left(\mathrm{C}_{2 \mathrm{v}}\right)$ (bs 2), borazine $\left(\mathrm{D}_{3 \mathrm{~h}}\right)$, hexazine $\left(\mathrm{D}_{6 \mathrm{~h}}\right)$, $\mathrm{N}_{6} \mathrm{H}_{2}^{2+}\left(\mathrm{C}_{\mathrm{s}}\right), \mathrm{N}_{6} \mathrm{H}_{4}^{4+}\left(\mathrm{C}_{\mathrm{s}}\right), \mathrm{C}_{7} \mathrm{H}_{7}^{+}\left(\mathrm{D}_{7 \mathrm{~h}}\right)$ (bs 3$), \mathrm{C}_{6} \mathrm{H}_{6} \mathrm{~N}^{+}$ $\left(\mathrm{C}_{2 \mathrm{v}}\right)$ (bs 3), $\mathrm{C}_{5} \mathrm{H}_{6} \mathrm{NB}\left(\mathrm{t}_{1}, \mathrm{C}_{\mathrm{s}}\right)$ (bs 3), $\mathrm{C}_{5} \mathrm{H}_{6} \mathrm{NB}\left(\mathrm{t}_{2}, \mathrm{C}_{\mathrm{s}}\right)$, $\mathrm{C}_{5} \mathrm{H}_{6} \mathrm{NB}\left(\mathrm{t}_{2}, \mathrm{C}_{1}\right), \mathrm{BC}_{6} \mathrm{H}_{7}\left(\mathrm{C}_{2 \mathrm{v}}\right)$ (bs 1$), \operatorname{Cotp} 2\left(\mathrm{D}_{8 \mathrm{~h}}\right)$ (bs 1), naphtalene $\left(D_{2 h}\right)$ (bs 3), indole $\left(C_{s}\right)$, An10 $\left(D_{10 \mathrm{~h}}, C_{2}\right)$, anthracene $\left(D_{2 h}\right)$, phenanthrene $\left(C_{2 v}\right)$, An11p1 $\left(C_{1}\right), \operatorname{An} 12 \mathrm{p} 2\left(C_{1}\right), \operatorname{An} 14\left(D_{14 h}, D_{7 h}, C_{1}\right)$, naphtacene $\left(D_{2 h}\right)$, An18 $\left(D_{18 h}, D_{9 h}, C_{1}\right)$, pentacene $\left(D_{2 h}\right)$, hexacene $\left(D_{2 h}\right)$, hexaphene $\left(C_{s}\right)$.

\section{SUBSTITUTED AROMATIC-LIKE SYSTEMS}

Toluene, aniline, phenol $\left(\mathrm{C}_{\mathrm{s}}\right)$ (bs 3), phenolium cation $\left(C_{s}\right)$, phenone, 2-methyl-indole, 3-methylindole, salicylamide (bs 3), mivazerol, protonated mivazerol.

\section{ANTIAROMATIC SYSTEMS}

\begin{tabular}{ll} 
Molecular systems (SG) & Calculation levels \\
\hline Cyclopropyl anion or $\mathrm{C}_{3} \mathrm{H}_{3}^{-}\left(\mathrm{D}_{3 \mathrm{~h}}\right)$ & $\mathrm{CAS}(4,7) / 6-31+\mathrm{G}^{* *}$, \\
& $\mathrm{UHF}(\mathrm{alt}) / 6-31+\mathrm{G}^{* *}$, \\
& $\mathrm{UHF}(\mathrm{reop}) / 6-31+\mathrm{G}^{* *}$ \\
& $\mathrm{CAS}(4,4) / 6-31 \mathrm{G}^{* *}$, \\
Cyclobutadiene $\left(\mathrm{D}_{4 \mathrm{~h}}\right)$ & $\mathrm{UHF}($ alt $) / 6-31 \mathrm{G}^{* *}$, \\
& $\mathrm{UHF}($ reop)/6-31G** \\
& $\mathrm{CAS}(4,5) / 6-31 \mathrm{G}^{* *}$, \\
Cyclopentadienyl cation & $\mathrm{UHF}($ alt $) / 6-31 \mathrm{G}^{* *}$, \\
or $\mathrm{C}_{5} \mathrm{H}_{5}^{+}\left(\mathrm{D}_{5 \mathrm{~h}}\right)$ & $\mathrm{UHF}(\mathrm{reop}) / 6-31 \mathrm{G}^{* *}$ \\
& $\mathrm{RHF} / 6-31 \mathrm{G}^{* *}$, \\
Benzene dication $\left(\mathrm{D}_{6 \mathrm{~h}}\right)$ & $\mathrm{UHF}($ alt $) / 6-31 \mathrm{G}^{* *}$, \\
& $\mathrm{UHF}($ reop $) / 6-31 \mathrm{G}^{* *}$, \\
& $\mathrm{CAS}(4,6) / 6-31 \mathrm{G}^{* *}$
\end{tabular}

\begin{tabular}{|c|c|}
\hline 7-annulene anion or $\mathrm{C}_{7} \mathrm{H}_{7}^{-}\left(\mathrm{D}_{7 \mathrm{~h}}\right)$ & $\begin{array}{l}\mathrm{CAS}(8,8) / 6-31+\mathrm{G}^{* *} \\
\text { UHF(alt) } / 6-31+\mathrm{G}^{* *} \\
\text { UHF(reop) } / 6-31+\mathrm{G}^{* *}\end{array}$ \\
\hline $\operatorname{Cot}\left(D_{8 h}\right)$ & $\begin{array}{l}\text { RHF/6-31G**, } \\
\text { UHF(alt)/6-31G } \mathrm{G}^{* *}, \\
\text { UHF(reop)/6-31G**, } \\
\text { CAS }(8,8) / 6-31 \mathrm{G}^{* *}\end{array}$ \\
\hline An10p2 ( $\left.D_{10 h}\right)$ & $\begin{array}{l}\text { RHF/6-31G, } \\
\text { UHF(alt)/6-31G, } \\
\text { UHF(reop)/6-31G, } \\
\text { CAS }(8,10) / 6-31 G\end{array}$ \\
\hline An12 ( $\left.D_{12 h}\right)$ & $\begin{array}{l}\text { UHF(alt)/6-31G, } \\
\text { UHF(reop)/6-31G, } \\
\text { CAS }(10,10) / 6-31 G\end{array}$ \\
\hline An14p2 $\left(D_{14 h}\right)$ & UHF(alt)/6-31G \\
\hline
\end{tabular}

\section{Acknowledgments}

GD is chercheur qualifié of the FNRS, Brussels.

\section{References}

1. Thouless, D. J. The Quantum Mechanics of Many-Body Systems; Academic: New York, 1961.

2. Adams, W. H. Phys Rev 1962, 127, 1650.

3. Löwdin, P. O. Rev Mod Phys 1963, 35, 496.

4. Koutecky, J. J Chem Phys 1967, 46, 2443.

5. Cisek, J.; Paldus, J. J Chem Phys 1967, 47, 3976.

6. Lefebvre, R.; Smeyers, Y. G. Int J Quant Chem 1967, 1, 403.

7. Löwdin, P. O. Adv Chem Phys 1969, 14, 283.

8. Paldus, J.; Cisek, J. J Chem Phys 1970, 52, 2919.

9. Ostlund, N. S. J Chem Phys 1972, 57, 2994.

10. Seeger, R.; Pople, J. A. J Chem Phys 1977, 66, 3045.

11. Fukutome, H. Int J Quant Chem 1981, 20, 955.

12. Löwdin, P. O; Calais, J. L.; Calazans, J. M. Int J Quant Chem 1981, 20, 1201.

13. Calais, J. L. Theor Chim Acta 1982, 61, 135.

14. Sykja, B.; Calais, J. L. Int J Quant Chem 1984, 25, 331.

15. Chambaud, G.; Levy, B.; Millie, P. Theor Chim Acta 1978, 48, 103.

16. Ooshika, Y. J Phys Soc Jpn 1957, 12, 1246.

17. Hilbert, A.; Coulson, C. A. J Phys B 1969, 2, 458.

18. Weiss, H.; Ahlrichs, R.; Häser, M. J Chem Phys 1993, 99, 1262.

19. Yamagushi, K. Theochem 1983, 12, 101.

20. Houk, K. N.; Yamagushi, K. In 1,3-Dipolar Cycloaddition Chemistry; Padwa, A., Ed.; Wiley: New York, 1985, p. 407; Vol. 2.

21. Kahn, S. D.; Hehre, W. J.; Pople, J. A. J Am Chem Soc 1987, 109,1871

22. Yoshioka, Y.; Yamaki, D.; Maruta, G.; Tsunesada, T.; Takada, K.; Noro, T; Yamagushi, K. Bull Chem Soc Jpn 1996, 69, 3395. 
23. Margenau, H.; Murphy, G. M. The Mathematics of Physics and Chemistry; Van Nostrand Company: London, 1968.

24. Pople, J. A.; Nesbet, R. K. J Chem Phys 1959, 22, 571.

25. Jørgensen, P. Annu Rev Phys Chem 1975, 26, 359.

26. McWeeny, R.; Dierksen, G. J Chem Phys 1968, 49, 4852.

27. (a) Paldus, J.; Veillard, A. Mol Phys 1978, 35, 445; (b) McKelvey, J. M.; Berthier, G. Chem Phys Lett 1976, 41, 476; (c) Kikuchi, O. Chem Phys Lett 1980, 72, 487.

28. (a) Dunlap, B. I. Phys Rev A 1983, 27, 2217; (b) Dunlap, B. I. Phys Rev A 1984, 29, 2902; (c) Dunlap, B. I. Adv Chem Phys 1987, 69, 287; (d) Dunlap, B. I. Chem Phys 1988, 125, 89; (e) Perdew, J. P.; Savin, A.; Burke, K. Phys Rev A 1995, 51, 4531; (f) Weiner, B.; Trickey, S. B. Int J Quant Chem 1998, 69, 452.

29. (a) Hohenberg, P.; Kohn, W. Phys Rev B 1964, 136, 864; (b) Kohn, W.; Sham, L. J. Phys Rev A 1965, 140, 1133; (c) Parr, R. G.; Wang, W. Density Functional Theory of Atoms and Molecules; Oxford: New York, 1989

30. Garratt, P. J. Aromaticity; Wiley: New York, 1986.

31. Frisch, M. J.; Trucks, G. W.; Schlegel, H. B.; Gill, P. M. W.; Johnson, B. G.; Robb, M. A.; Cheeseman, J. R.; Keith, T. A.; Petersson, G. A.; Montgomery, J. A.; Raghavachari, K; AlLaham, M. A.; Zakrzewski, V. G.; Ortiz, J. V.; Foresman, J. B.; Cioslowski, J.; Stefanov, B. B.; Nanayakkara, A.; Challacombe, M.; Peng, C. Y.; Ayala, P. Y.; Chen, W.; Wong, M. W.; Andres, J. L.; Replogle, E. S.; Gomperts, R.; Martin, R. L.; Fox, D. J.; Binkley, J. S.; Defrees, D. J.; Baker, J.; Stewart, J. P.; Head-Gordon, M.; Gonzalez, C.; Pople, J. A. Gaussian 94 (Revision D.4); Gaussian Inc.: Pittsburgh, PA, 1996.

32. Foresman, J. B.;Head-Gordon, M.; Pople, J. A.; Frisch, M. J. J Chem Phys 1992, 96, 135.

33. (a) Hegarty, D.; Robb, M. A. Mol Phys 1979, 38, 1795; (b) Eade, R. H. E.; Robb, M. A. Chem Phys Lett 1981, 83, 362; (c) Bernardi, F; Bottini, A.; Mc Dougall, J. J. W.; Robb, M. A.; Schlegel, H. B. Far Symp Chem Soc 1984, 19, 137.

34. (a) Moller, C.; Plesset, M. S. Phys Rev 1934, 46, 618; (b) Krishnan, R.; Pople, J. A. Int J Quant Chem 1978, 14, 91.

35. (a) Shaik, S. S.; Hiberty, P. C.; Lefour, J. M.; Ohanessian, G. J Am Chem Soc 1987, 109, 363; (b) Jug, K.; Köster, A. M. J Am Chem Soc 1990, 112, 6772; (c) Schütt, J.; Böhm, M. C. J Am Chem Soc 1992, 114, 7252.

36. Two $\operatorname{CASSCF}(6,8)$ types of calculation were performed: a CASSCF considering six electrons in eight $\pi$-type MO, noted PP-CAS $(6,8)$, and a CASSCF considering six electrons in five $\pi$-type and three $\sigma$-type MO, noted PS-CAS $(6,8)$. Let us note that PP-CAS $(6,6)$ calculations (note shown here) could provide the lowest singlet and $\pi \rightarrow \pi^{*}$ triplet states but not the excited $\pi \rightarrow \pi^{*}$ ones while the PP-CAS $(6,8)$ could. However, the lowest triplet state results from a $\pi \rightarrow$ $\sigma^{*}$ transition as obtained either at the HF, the CIS and the PS-CAS $(6,8)$ calculations.

37. Vancampenhout, N.; Dive, G.; Dehareng, D. Int J Quant Chem 1996, 60, 911.

38. Xie, Y.; Schaefer, H. F; Liang, G.; Bowen, J. P. J Am Chem Soc $1994,116,1442$.

39. Dunning, T. H., Jr.; Hay, P. J. In Modern Theoretical Chemistry; Schaefer, H. F., III, Ed.; Plenum: New York, 1976.

40. Yamagushi, K. Chem Phys Lett 1975, 35, 230.

41. Dehareng, D.; Dive, G.; Moradpour, A. Int J Quant Chem, accepted; ibid, Chem Eur J, submitted.

42. Coulson, C. A.; Altman, S. L. Trans Faraday Soc 1952, 48, 293.

43. Saxe, P.; Schaefer, H. F., III J Am Chem Soc 1983, 105, 1760.

44. Cooper, D. L.; Wright, S. C.; Gerratt, J.; Raimondi, M. J Chem Soc Perkin Trans II 1989, 255.

45. Cooper, D. L.; Wright, S. C.; Gerratt, J.; Hyams, P. A.; Raimondi, M. J Chem Soc Perkin Trans II 1989, 719.

46. Cooper, D. L.; Wright, S. C.; Gerratt, J.; Raimondi, M. J Chem Soc Perkin Trans II 1989, 263.

47. (a) Dewar, M. J. S.; Harget, A.; Haselbach, E. J Am Chem Soc 1991, 91, 7521; (b) Hrovat, D. A.; Borden, W. T. J Am Chem Soc 1992, 114, 5879 .

48. Kollmar, H.; Staemmler, V. Theor Chim Acta 1978, 48, 223.

49. Gallup, G. A. J Chem Phys 1987, 86, 4018.

50. Karadakov, P. B.; Gerratt, J.; Cooper, D. L.; Raimondi, M. J Phys Chem 1995, 99, 10186.

51. Hund, F. Z Physik 1925, 33, 345; ibid, 1925, 33, 855.

52. (a) Cohen-Tannoudji, C.; Diu, B.; Laloë, F. Mécanique Quantique; Hermann: Paris, 1973; (b) Jensen, F. Introduction to Computational Chemistry; Wiley: Chichester, 1999.

53. (a) Böhm, M. C.; Schulte, J.; Schütt, J.; Schedel-Niedrig, T.; Werner, H.; Schlögl, R. Int J Quant Chem 1997, 65, 333; (b) Böhm, M. C.; Schütt, J.; Philipp, S. Int J Quant Chem 1998, $69,727$.

54. Weiner, P.; Kollman, P. J Comput Chem 1981, 2, 287. 